\title{
Living the good life in a non-growth world Investigating the role of hierarchy
}

\author{
Blair Fix \\ February 18, 2021
}

\begin{abstract}
Humanity's most pressing need is to learn how to live within our planet's boundaries - something that likely means doing without economic growth. How, then, can we create a non-growth society that is both just and equitable? I attempt to address this question by looking at an aspect of sustainability (and equity) that is not often discussed: the growth of hierarchy. As societies consume more energy, they tend to become more hierarchical. At the same time, the growth of hierarchy also seems to be a key driver of income/resource inequality. In this essay, I review the evidence for the joint relation between energy, hierarchy and inequality. I then speculate about what it implies for achieving a sustainable and equitable future.
\end{abstract}

Note: This essay was written for and supported by the Seoul Platform for Initiating Discourses on an Equitable and Resilient Society.

\section{Sustainability or bust}

For the past 200 years, humanity has conducted an unintended experiment. The (tacit) research question is this: how much of the Earth's resources can one species consume? We have yet to find out the answer ... nor do we want to.

By nearly all indicators, humanity is doing immense damage to the biosphere. We are using non-renewable resources at a feverish pace (Heinberg, 2007). We may be causing the Earth's sixth mass extinction (Kolbert, 2014). And perhaps most alarmingly, we are changing the climate in a way that could put civilization at risk (Paul R Ehrlich \& Ehrlich, 2013). It is time, then, for 
our unintended experiment to stop. Instead of plumbing the depths of unsustainability, we must do the opposite. Humanity must become sustainable. The question is, how?

In one sense, the answer is simple. Our impact on the environment is a function of two things: (1) how many people there are; and (2) the amount of resources each person consumes (Paul R. Ehrlich \& Holdren, 1971). Becoming sustainable is therefore easy in principle. It requires reducing the human population and reducing resource consumption per person. And yet beneath this simple formula is a web of complexity (and confusion). Here, I will ignore population reduction (which is itself controversial). I will focus on achieving sustainability by reducing per capita resource use.

Mainstream discussions of sustainability tend to focus on efficiency (Hawken, 2000; Weizsäcker, 1997). Outside the mainstream, however, more emphasis is put on directly reducing resource use by consuming less. This thinking goes by many names, but here I will refer to it as 'degrowth'. The idea is that instead of pursuing economic growth, we should learn how to live with less. We should voluntarily 'degrow' the economy (Kallis, 2011; Latouche, 2004).

My view is that degrowth is the only sound option for becoming sustainable. But how can we achieve degrowth while also creating a society that is equitable and just? This is the question that I seek to address.

\section{The human need for equity}

Sustainability does not require equity. That is because our impact on the Earth is a function of the average resource use per person. To the Earth, it does not matter if we use resources equitably, or if one person consumes almost everything and the rest of us starve. It does, however, matter to humans.

There is little that is so toxic to human welfare as rampant inequality. When inequality increases, human well-being gets worse (Richard G Wilkinson, 2001, 2002; Richard G. Wilkinson \& Pickett, 2009). This is perhaps one of the most robust findings of the last few decades of social science. In the landscape of human evolution, it is a finding that is unsurprising. Humans are a social species. As such, our welfare is inseparable from our relations with others. If these relations are unequal, those at the bottom do worse - regardless of their absolute standard of living. This is not a quirk, but rather a feature we share with other primates (Sapolsky, 2005). Among social animals, relationships matter.

Assuming we want an equitable society, how can we achieve it while consuming less? Because voluntary degrowth remains largely untested, there are 
no definitive answers. But I think there are hints. What I will explore, in this essay, is how resource use and equity both relate to hierarchy.

Hierarchy - the ranking of individuals — is part of most social species (Barroso, Alados, \& Boza, 2000; Guhl, Collias, \& Allee, 1945; Kondo \& Hurnik, 1990; Meese \& Ewbank, 1973; Sapolsky, 2005; Uhrich, 1938). Humans, however, have taken this form of organization to a new level. We are unique among animals in having developed an explicit chain of command in which each superior direct subordinates. This chain of command allows large human groups to function cohesively in a way that no animal group can (Turchin, 2016). But hierarchical organization comes at a cost. Hierarchy concentrates power, and that leads to despotism and inequality. Less intuitively, hierarchy also appears to be energy intensive. As we organize in larger hierarchies, we tend to consume more energy.

\section{Energy, hierarchy and inequality}

This essay explores the joint relation between energy, hierarchy and inequality. It is organized in three parts. In Part 1, I review the link between energy and the growth of hierarchy. I then speculate about what this link means for a transition to renewable energy. In Part 2, I discuss how hierarchy relates to inequality. I show that although energy degrowth may make hierarchies smaller, this change is (on its own) unlikely to reduce inequality. Instead, I find that what is most important for reducing inequality is to rein in something I call 'hierarchical despotism' - the conversion of hierarchical power into income. Building on this result, in Part 3 I speculate about pathways to equitable degrowth.

\section{Part 1: Energizing hierarchy ${ }^{1}$}

That humans organize in hierarchy is a fact that should surprise no one. Our working lives are dominated by taking and giving orders (Marglin, 1974). What many people do not know, however, is that hierarchy has a direction - towards more of it.

This trend is recent. Only in the last two centuries has hierarchy grown significantly. While the exact reasons for this growth remain poorly understood, what we can say (with reasonable certainty) is that hierarchy is connected to energy.

\footnotetext{
${ }^{1}$ I thank Shimshon Bichler and Jonathan Nitzan for coining the phrase 'energizing hierarchy' (Bichler \& Nitzan, 2020).
} 
I will make the case for this energy-hierarchy connection using indirect evidence. (I do so because direct data for the growth of hierarchy does not yet exist.) The first strand of evidence comes from institution size. As energy use increases, institutions tend to become larger. Figure 1 shows the trend for business firms. In the main panel, each dot represents a country. I have plotted the country's average firm size (measured in terms of the number of employees) on the vertical axis, and energy use per capita on the horizontal axis. The trend is clear: as countries use more energy, firms tend to get larger.

What we cannot tell, by looking at averages, is how this firm growth happens. It could be that the average grows because most firms get slightly larger. It turns out, however, that this is not what happens. As energy use increases, most firms remain small. Instead, average firm size grows because a few large firms get larger still.

We can see this trend in the inset panel in Figure 1. Here I plot the size distribution of firms across countries, grouped by energy quartile. (In the main plot, I have used color to indicate each quartile.) The horizontal axis shows firm size, while the vertical axis shows the portion of firms that are the corresponding size. What is important here are two things. First, most firms are small - and this remains so regardless of energy use. Second, what changes with energy is the number of large firms. More energy means more large firms. It is a rich-getricher dynamic. Most firms stay small, but a few large ones grow larger still.

Similar trends hold for government. As countries use more energy, government tends to grow larger. For a thorough review of the energy-institution-size evidence, see Fix (2017).

The firm-size evidence hints that hierarchy grows with energy use. Here is the reasoning. From our working lives, we know that firms are hierarchically organized. Therefore, as firms grow larger, it follows that hierarchy increases. This, I believe, is sound logic. But is there evidence that it is true?

Figure 2 shows one strand of evidence that confirms our reasoning. Here, I look at how the managers' share of employment relates to energy use. The idea is that the relative number of managers provides a window into the amount of hierarchy in a society. The reason is simple: a manager's job is to command others. It is a job that, without hierarchy, could not exist. So the growth of managers is indirect evidence for the growth of hierarchy.

What Figure 2 shows is that the relative number of managers tends to grow with energy use. Note, however, that the energy-manager trend is nonlinear. As energy use increases, the relative number of managers grows rapidly at first, but 


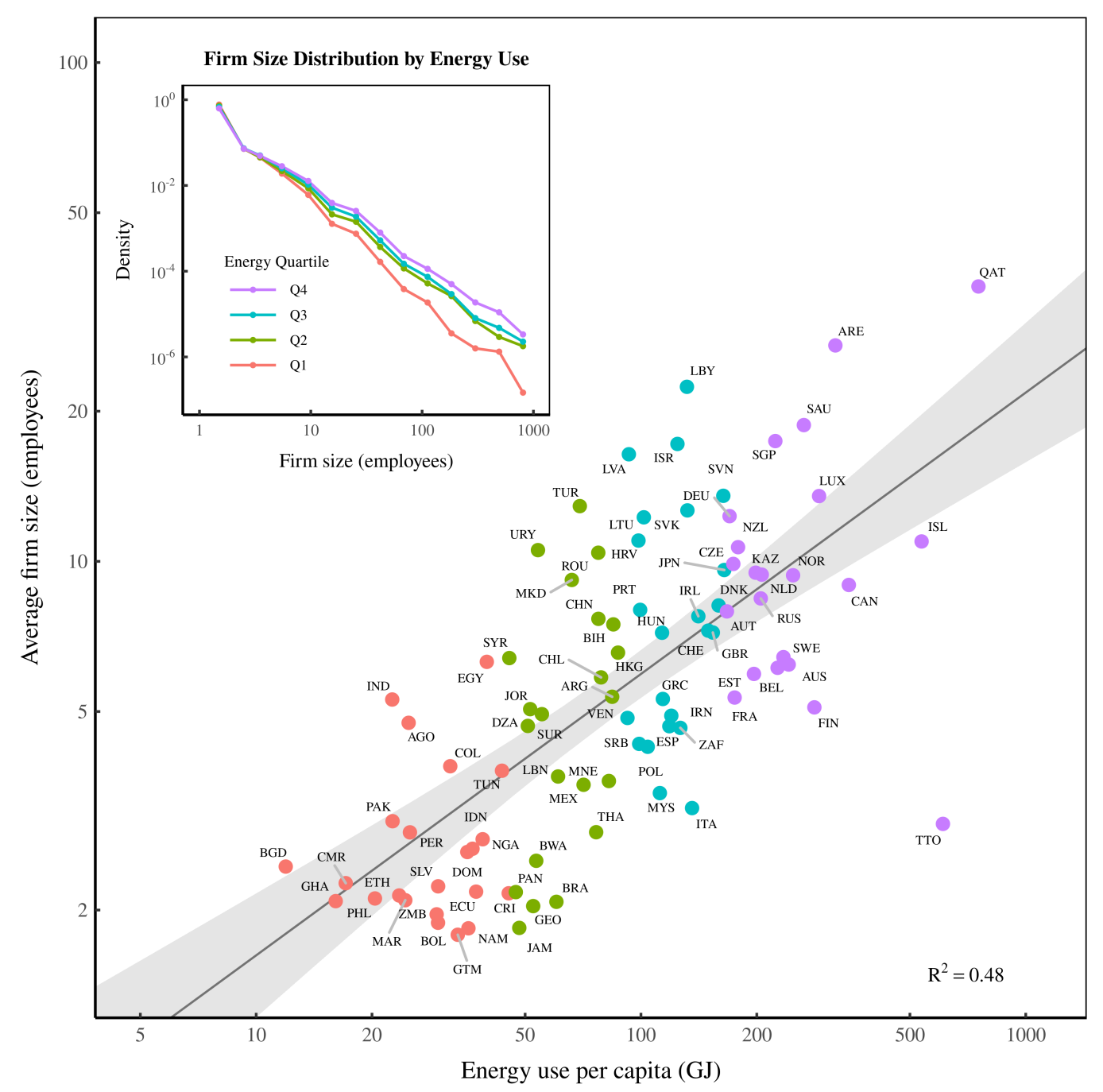

Figure 1: As countries use more energy, firms get larger

The main panel shows how average firm size (within countries) changes with energy use per capita. Color indicates a country's energy quartile. I have labelled countries using alpha-3 codes. The inset plot shows the firm size distribution within each respective energy quartile. Sources and methods.

then plateaus.

This non-linear trend, it turns out, is exactly what we expect if hierarchy grows with energy use. The reason has to do with a basic feature of hierarchical organization. In a hierarchy, the number of ranks tends to grow with the logarithm of group size (see Fix, 2015a for a derivation). When a hierarchy is small, adding more members quickly adds more ranks, and hence, more managers. But as the group continues to grow, new ranks are added less rapidly. So 


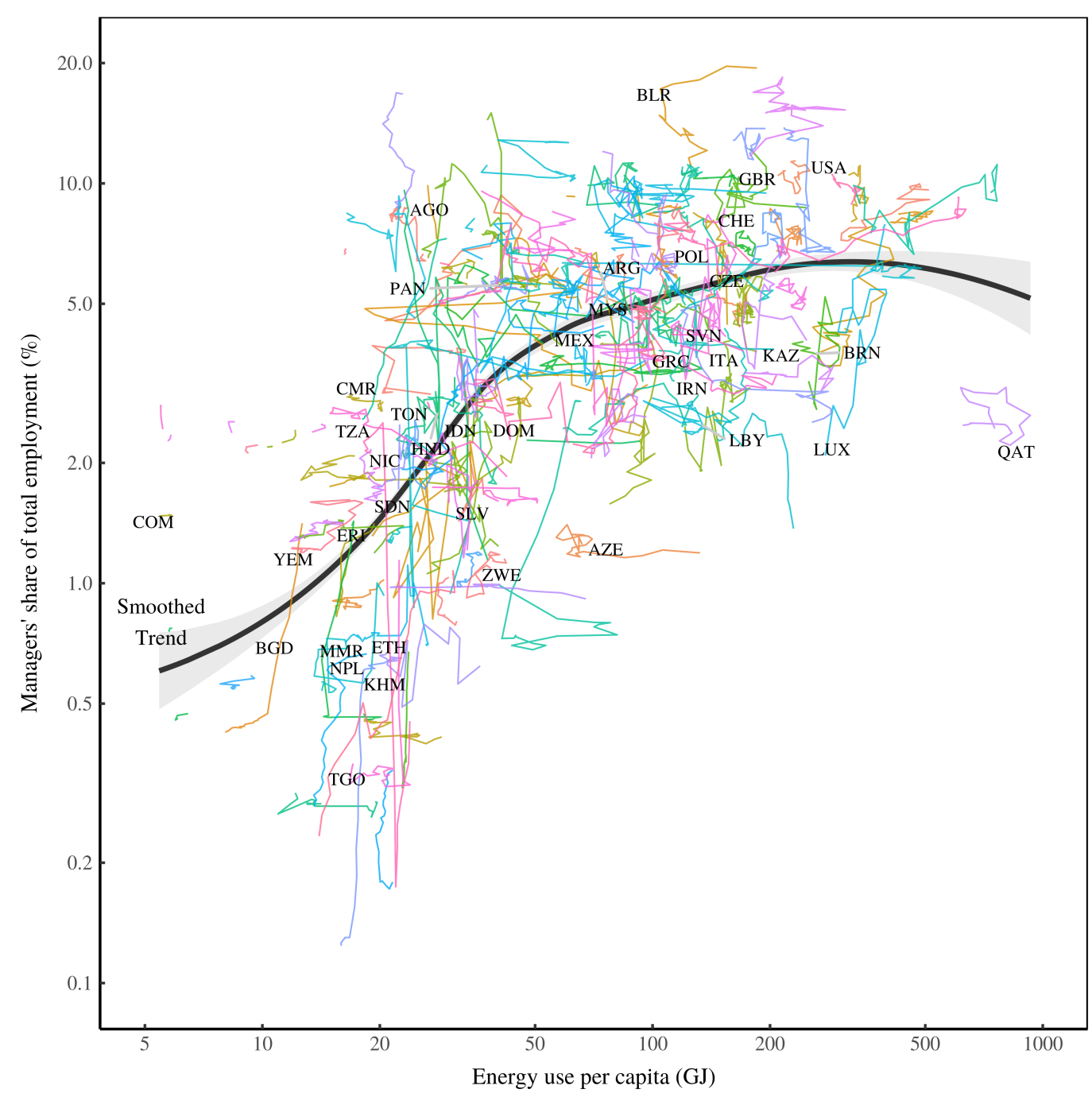

Figure 2: As countries use more energy, the relative number of managers increases

Each line represents the path through time of a country. The black line is the smoothed trend across all countries. I have labelled select countries with their alpha- 3 codes. Sources and methods.

the growth of managers slows. Eventually, the hierarchy becomes so large that the portion of people in top ranks becomes constant. The relative number of managers stops growing.

When we formalize this model, it produces the trend shown in Figure 3. Here, black points are the empirical data (the same as in Fig. 2). The rainbow is the model prediction, where color indicates the span of control (how many subordinates each superior controls in a hierarchy). The inset panel shows how 


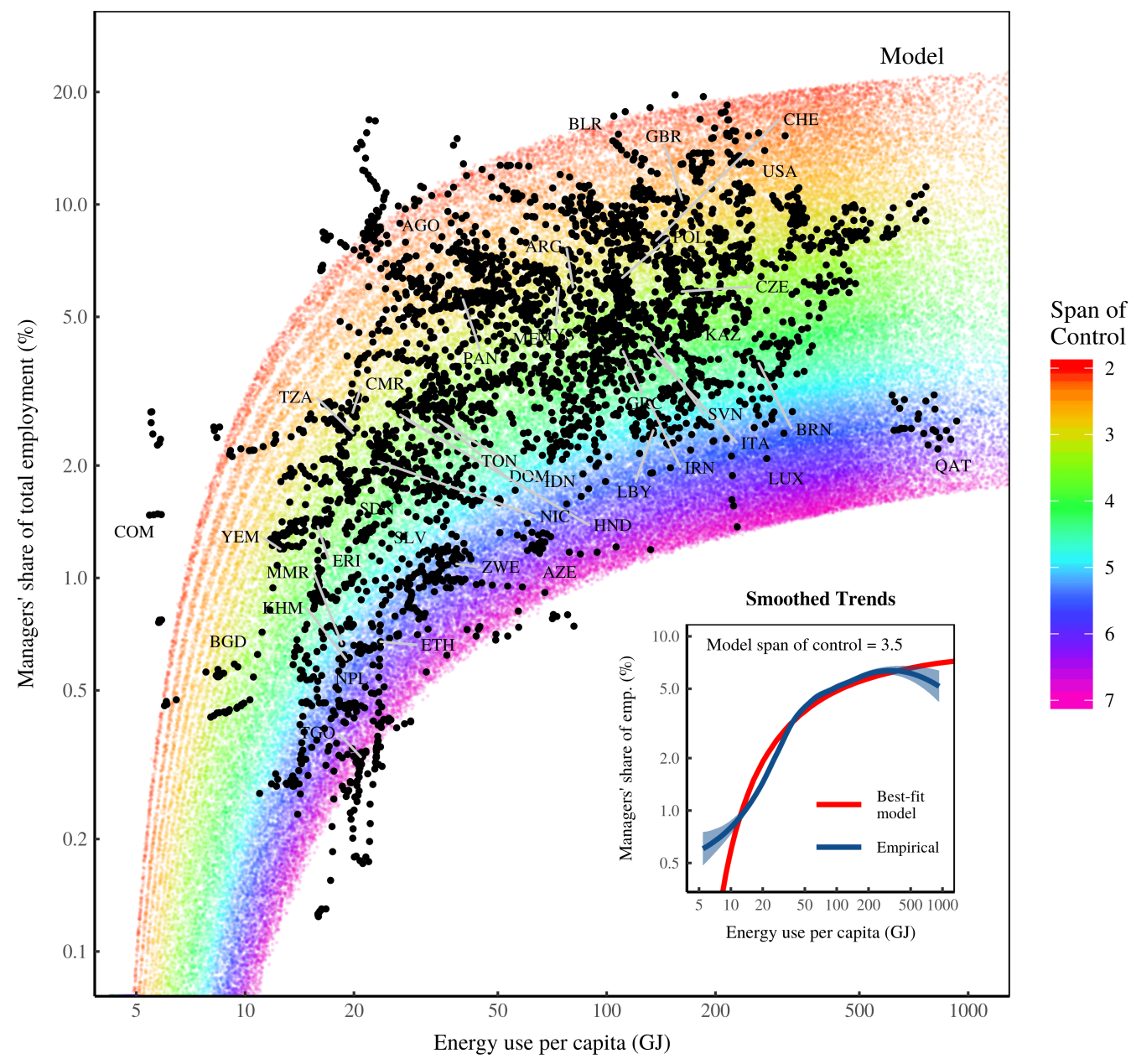

Figure 3: A model of the growth of managers

Black points are empirical observations for energy use and the relative number of managers (the same data as in Figure 2). Colored points represent the model results. Color indicates the span of control in the model - the number of subordinates controlled by each superior. The inset panel shows how the best-fit model relates to the empirical trend across all countries. Sources and methods.

the best-fit model compares to the empirical trend. The fit is excellent. The model therefore suggests that managers become more common (as energy use increases) because hierarchy is growing. (See Fix, 2020a for details about the model.)

To summarize, there is strong (but indirect) evidence suggesting that: (1) as energy use increases, institutions become larger; and (2) this institution growth can be viewed as an increase in social hierarchy. 


\section{Why hierarchy?}

As societies consume more energy, why do they become more hierarchical? The short answer is that we do not know. The scientific study of how energy relates to hierarchy is in its infancy. As such, we have no definitively-correct theory to explain what is going on. The long answer, however, is that we do have some guesses. There are three plausible reasons why using more energy is associated with more social hierarchy.

One possibility is that energy use drives the growth of hierarchy. In this scenario, hierarchy is not necessary for harvesting energy, but is instead a pernicious side effect. The basic idea is that as societies harvest more energy, they produce a growing surplus. But instead of being used by the population, this energy surplus is expropriated by elites who use it to support lavish lifestyles. In this view, elites are a burden to the rest of society. This hierarchy-as-pariah scenario fits well with 'conflict' theories of social stratification (Dahrendorf, 1959; Marx, 1867; Mills, 1956; Tumin, 2018).

Another possibility is that causation is reversed - meaning the growth of hierarchy causes society to consume more energy. It is a scenario that can play out in two different ways.

First, it could be that hierarchy is essentially a driver of waste. The idea is that maintaining hierarchical organization is energy intensive. As hierarchy grows, it therefore drives the consumption of energy. Crucially, though, this energy serves no purpose other than to maintain the hierarchy itself (Bichler \& Nitzan, 2020; Fix, Bichler, \& Nitzan, 2019). As an example of this process, consider the US Pentagon. It typically consumes the equivalent of about 170 million barrels of oil - roughly $80 \%$ of all the energy consumed by the US government (Crawford, 2019). Besides fattening the belts of military contractors, it seems unlikely that this profligate energy use greatly benefits the rest of US society. Or consider the age-old example of the Egyptian pyramids. They required a colossal investment of energy, yet served no purpose other than to appease the Pharoahs' vanity. This hierarchy-as-a-driver-of-waste scenario fits well with the theory of monopoly capital, which highlights the wasteful tendencies of capitalism (Baran \& Sweezy, 1966; P. M. Sweezy, 1942).

Second, it could be that hierarchy drives energy use, but not in a wasteful way. Instead, it may be that hierarchical organization is necessary for using more energy. Why might this be? A plausible reason is that consuming more energy requires greater social coordination. The idea, then, is that hierarchy is the goto method for coordinating large groups. The hierarchical chain of command 
allows thousands (even millions) of people to coordinate their actions - coordination that may be necessary for consuming greater quantities of energy (Fix, 2015b, 2017). This hierarchy-as-coordinator scenario is consistent with functionalist theories of social stratification (Davis \& Moore, 1945; Parsons, 1940).

At present, there is not enough evidence to decide which theory is correct. But my suspicion, though, is that each one has an element of truth. Let's start with the idea that hierarchy is necessary for consuming energy. I find this functionalist explanation plausible because it seems unlikely that a form of social organization that has persisted (and spread) for more than 5,000 years provides no social benefit.

It is important, though, to view this benefit in evolutionary (not hedonistic) terms (Fix, 2019a). That is because there is convincing evidence that members of early hierarchical agrarian societies were actually less healthy than their egalitarian hunter-gather relatives (Boix \& Rosenbluth, 2014). Viewed through a hedonistic lens, the spread of hierarchy makes little sense. Why would humans choose to organize using a social form that made them less healthy?

The likely answer is that evolution (whether genetic or cultural) cares not for welfare ... it cares for differential reproduction. And on that front, hierarchical organization may have been a clear winner. For one thing, there is evidence that hierarchical agrarian societies had higher fertility rates than egalitarian huntergatherers (Bentley, Goldberg, \& Jasieńska, 1993). The biggest advantage of hierarchy, though, may have come in warfare. Peter Turchin (2016) argues that hierarchical societies likely spread for a simple reason: their large, hierarchical armies defeated the small bands organized by hunter-gatherers.

Why couldn't egalitarian societies muster the same sized armies? Again, Turchin thinks there is a simple answer - the human brain. In the 1990s, the anthropologist Robin Dunbar discovered that among primates, brain size correlates strongly with group size. The larger the group, the larger the species' brain (Dunbar, 1992). This led Dunbar to theorize that primate brain size is a key constraint on group size. When Dunbar extrapolated this relation to humans, it predicted a group size of about 150 .

Today, this number is clearly wrong - humans live in groups with hundreds of thousands of members. So is Dunbar's theory moot? Perhaps not. Dunbar's predicted group size (150 people) is actually slightly larger than the size of modern hunter-gather bands (K. R. Hill et al., 2011). If this small band was our ancestral state, then it is consistent with Dunbar's hypothesis. But how, then, did we eventually break the mould? Peter Turchin thinks that the answer was hierarchy. 
In a hierarchical chain of command, Turchin notes, individuals need to interact only with their direct superior and their direct subordinates. The chain of command therefore limits the number of relations that any one person must maintain, providing a clever mechanism to sidestep our social limitations (Turchin \& Gavrilets, 2009). By doing so, hierarchy allows human groups to grow far beyond Dunbar's number. When early agrarian societies adopted hierarchical relations, Turchin argues that they could suddenly organize large armies. Egalitarian hunter-gatherers, however, were stuck in small bands never much greater than Dunbar's number. Needless to say, the large hierarchical armies won. As they did, egalitarianism died out and hierarchy spread.

If we were to put this evolutionary tale in motto form, it would be this: hierarchy spread because it could, not because it was good. This caveat is essential, because there is overwhelming evidence that hierarchy leads to abuses of power. The idea is simple: power corrupts. Given the chance, those with hierarchical power will inevitably use it for their own gain. It's a fact that anthropologists have repeatedly discovered. Here, for instance, is archaeologist Brian Hayden commenting on his study of Mayan villages:

I was completely astonished at the results from village after village ... that showed that the local elites provided essentially no help to other members of the community in times of crisis, but instead actually devised means of profiting from the misfortunes of others.

(Hayden, 2001, emphasis in original)

These abuses of power are why it is essential, I believe, to treat hierarchy as a double-edged sword. Yes, hierarchy probably functions to coordinate groups, and by so doing, allows the exploitation of greater amounts of energy. But hierarchy also comes with a cost - namely despotism. I will explore this cost in detail in Part 2.

\section{When exploiting energy becomes a liability}

The reward to hierarchical organization, I have argued, is the ability to organize in larger groups that can exploit more energy. Today, however, this reward has turned into a liability.

The problem, again, is evolutionary. Hierarchy will tend to spread if it allows hierarchical groups to out-compete non-hierarchical groups. But just because hierarchy spreads does not mean that it is good for either humanity or the Earth. 
Evolution cares not for the health of the biosphere. It cares only for what survives. Today, this fact is clear. If energy-guzzling hierarchical groups continue to spread (at the expense of less energy profligate groups), the result will be ecological disaster.

In some ways, this problem will solve itself. If hierarchical groups push the biosphere to the brink, there will come a point when they can no longer sustain their lifestyles. When this happens, energy-intensive forms of organization will become a disadvantage, and they will disappear (much like extinct species). By so doing, the problem of over-consumption goes away.

Yet if we opt for this laissez-faire 'solution', the road to sustainability will be paved with massive environmental destruction. Yes, the problem will eventually solve itself. But there is no guarantee that humanity will survive to see the results.

\section{Transitioning to renewable energy may require degrowth}

To avoid environmental disaster, virtually all sustainability researchers agree that humanity needs to ween off fossil fuels and transition to renewable energy. I will take this transition as a given. There simply is no alternative.

What remains controversial, however, is whether this transition should also involve using less energy. The degrowth movement argues that we should choose to use less energy (and less of everything else as well). But what if this is not a choice? What if transitioning to renewable energy requires energy degrowth. Although unpopular, this latter claim has surprising evidence backing it up. Historical trends suggest that a transition to renewable energy may come with a baked-in need for degrowth.

Before I discuss the evidence for this claim, permit me a brief foray into human history. If we were to simplify human history into a single dimension, I think it should be this: the centralization of energy. Humans began as a wandering species who roamed the Earth harvesting sparse resources. For hundreds of thousands of years, little changed. Then came agriculture. By learning how to grow our own crops and raise our own livestock, we were able to centralize our energy supply. The result was the first civilizations.

After this transition came another period of relative stasis. Then came fossil fuels. These fuels - the stored energy from millions of years of biomass production - were orders of magnitude more concentrated than agriculture. The result was the centralization of our energy supply like we had never seen before. 
The point of this stylized history is to highlight a plausible connection between the centralization of energy production and the rate at which we use this energy. In simple terms, more centralization equals more energy consumption.

Recent US history gives surprising evidence to support this claim. Figure 4 tells the story. I have plotted here the indexed growth of US electricity use per capita. Since 1902, the average US individual increased their electricity use by roughly a factor of 200. This monumental growth of energy consumption is wellknown. But what is less well-known is that this growing consumption was met in large part by building bigger power plants (not by building more small-scale plants).

To see this fact, look at the red curve in Figure 4. It shows the growth in the average size of US electric power plants. Over the 20th century, the average US power plant grew larger (in terms of nameplate capacity) by a factor of 70 . This indicates that the growing demand for electricity was met mostly by building larger power plants. Interestingly, when electricity use levelled off (after 1970) so did power-plant size. (The inset panel in Figure 4 shows the correlation between electricity use and power-plant size.)

What Figure 4 shows, then, is the process of energy centralization in action. In principle, the US could have produced more electricity by building a growing number of small-scale power plants. But this is historically not what happened. Instead, growing demand for electricity was met by building larger power plants. In other words, an increasing volume of energy (mostly in the form of coal) was brought to single plant where it was transformed into electricity. This is energy centralization in action.

The trend towards energy centralization has important implications for the transition to renewable energy. It suggests that switching to renewable energy may inevitably result in degrowth. Here is why.

Before humans touch them, fossil fuels already come in a relatively concentrated form - vast reserves of stored solar energy. That makes them easy to centralize. (It is standard practice, for instance, to build massive coal power plants close to coal strip mines.) The same is not true for renewable energy, which tends to come in diffuse form. This is especially true of solar energy. Yes, the sun bathes the Earth in enormous quantities of energy. But this energy is diffuse. That means we have to do the work of centralizing it ourselves. So compared to fossil fuels, renewable energy is generally more difficult to centralize. For this reason, renewable energy installations are likely to be small.

This logic is born out by the evidence in Figure 5. I plot here the size distri- 


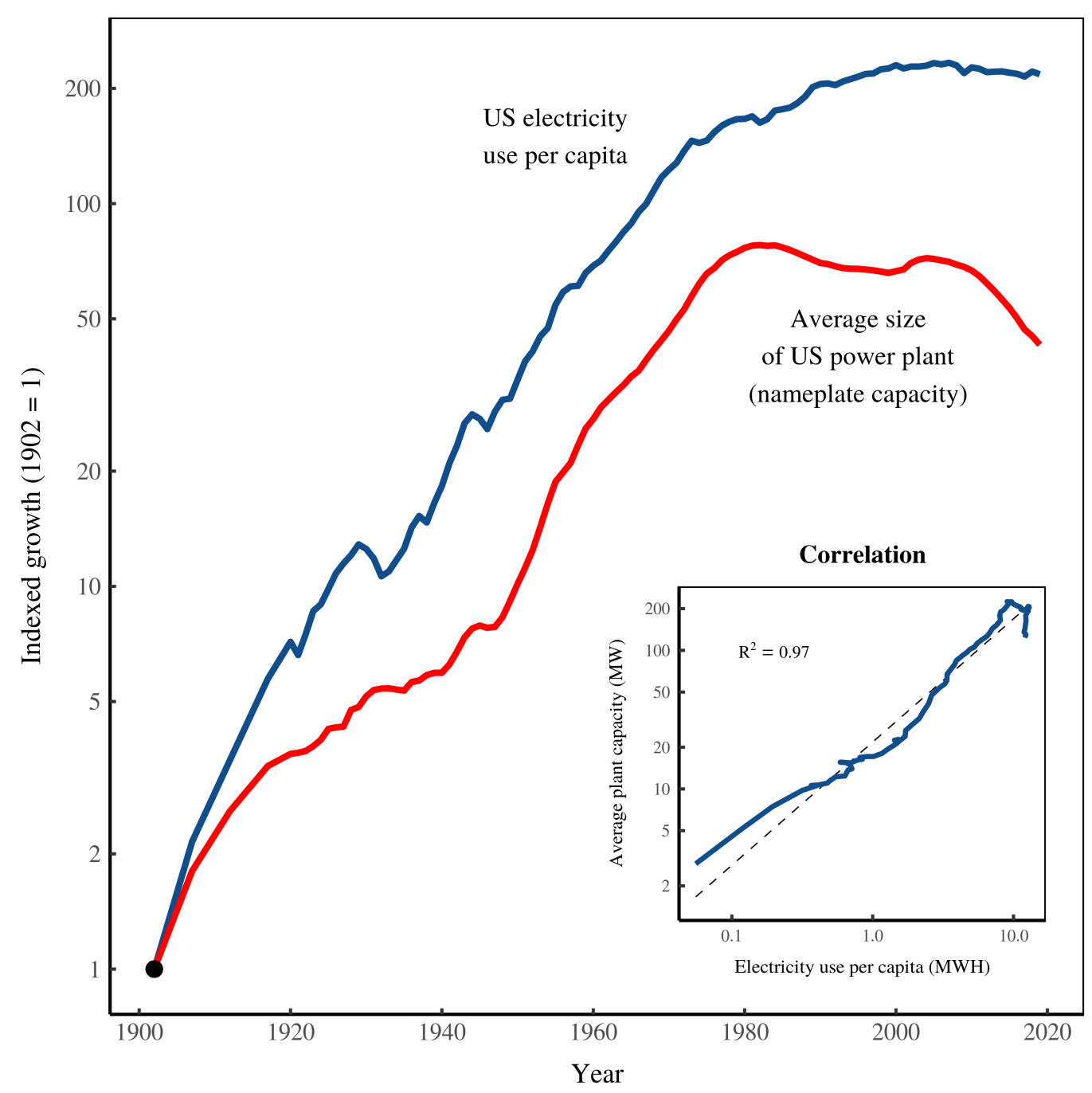

Figure 4: Using more electricity by centralizing generation capacity

I plot here the growth of US electricity per capita (blue) and the growth in the average size of US electricity power plants (red), as measured by nameplate capacity. In the main panel, both series are indexed to equal 1 in the year 1902. The inset panel shows the correlation in the non-indexed data. Sources and methods.

bution of active US power plants, differentiated by their energy source. (Note that the vertical axis uses a log scale, so each tick mark indicates a factor of 10.) Plants that use non-renewable energy are shown in red. Plants that use renewable energy are shown in blue. It is easy to see the difference between the two types of generation. Power plants that use non-renewable energy are, on average, far larger than those that use renewable energy. (The exception is petroleum-powered plants, which tend to be small.) 


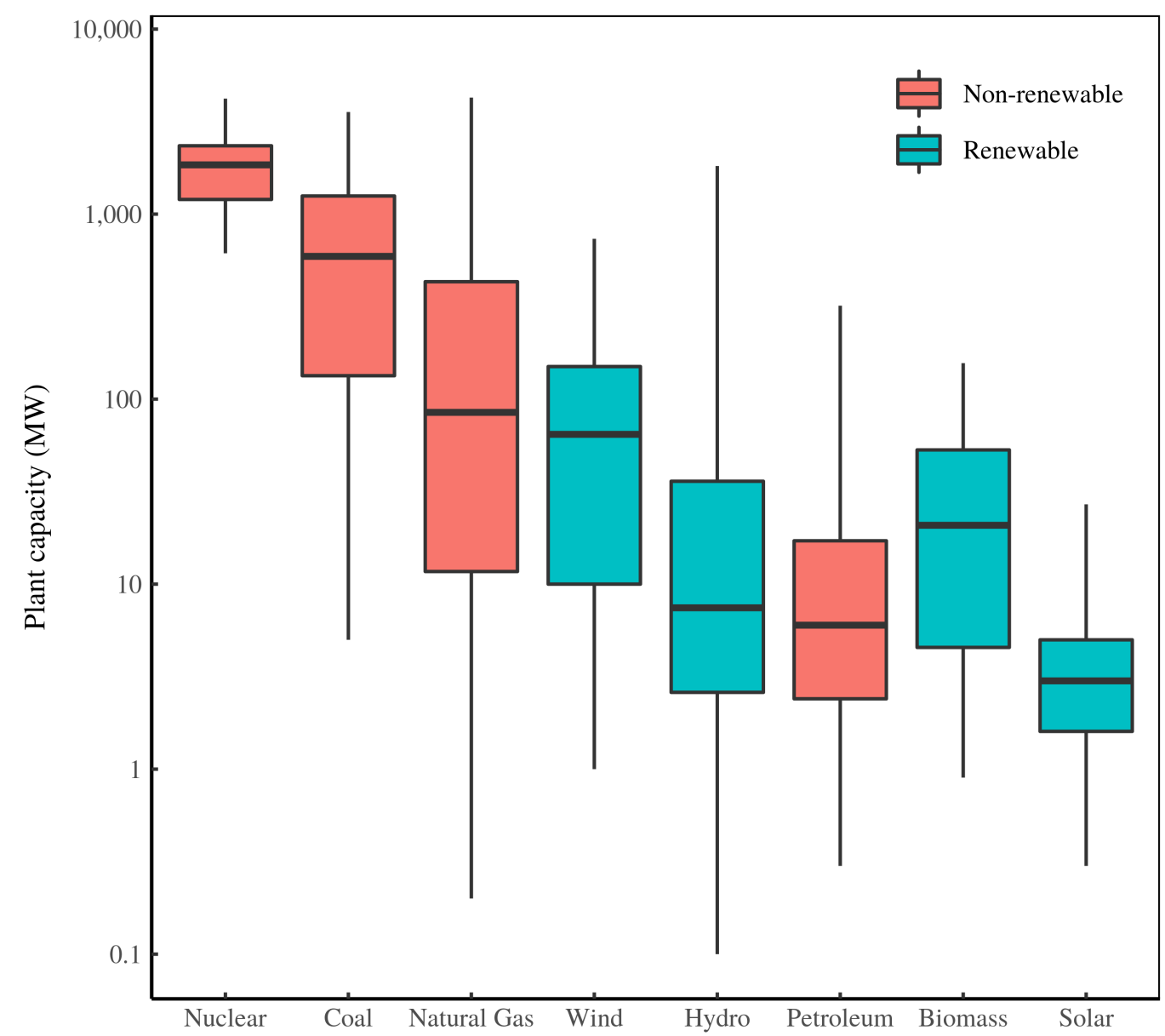

Figure 5: The size distribution of US electric power plants by energy source Boxplots show the size distribution (nameplate capacity) of active US power plants as a function of energy source. I have ranked the energy sources (left to right) by decreasing mean capacity. Note that because plant sizes are highly skewed, the mean size can differ significantly from the median size (the horizontal line in the boxplot). Sources and methods.

The size difference between the two types of plants (renewable vs. nonrenewable) likely comes down to the energy source itself. Non-renewable energy tends to come in a concentrated form, and so is easier to centralize. Renewable energy, in contrast, tends to come in a diffuse form, and so is more difficult to centralize.

As an example, look at the size difference (in Fig. 5) between nuclear plants and solar farms. Nuclear plants harvest the densest energy source ever exploited (fissile uranium). It is no surprise, then, that these plants are highly centralized, having an average capacity of about 1800 MW. Solar farms, in contrast, harvest 
one of the most diffuse energy sources on Earth. Unsurprisingly, these farms are far less centralized than nuclear power plants. Their average capacity is a mere 11.3 MW - about 150 times smaller than the average nuclear plant.

For many solar advocates, this size difference seems unimportant. Yes, solar installations tend to be smaller than fossil-fuel plants. But so what? Can we not meet our current energy needs simply by building many small solar plants?

Such a solution seems plausible ... until we consider the evidence in Figure 4. Historically, the growth of electricity use was achieved by centralizing energy - converting increasing quantities of primary energy at a single location. A transition to renewable energy (especially solar) would reverse this trend, moving instead towards energy decentralization. Yet if the historical connection between electricity use and plant size holds, this decentralization comes with a hard-wired need to use less energy.

Suppose that in the future, the US transitions to 100\% solar-powered electricity. Suppose also that the average size of solar installations remains the same as today. That means that the average power plant would drop in size by a factor of 10. Now suppose that the historical trend between plant size and electricity use continues to hold. This implies that per capita electricity use would also drop by about a factor of $10 .^{2}$

What this analysis suggests, then, is that a transition to renewable energy may come with the baked-in need for energy degrowth. It simply may not be possible to meet current energy demands using renewable energy alone. One could use this as an argument to justify continued fossil fuel use. A saner argument, however, would be that curbing our fossil-fuel habit may require degrowth.

The caveat, of course, is that the historical trend between plant size and electricity use may not hold in the future. In the last decade, for instance, US power-plant size has decreased on average by about $40 \%$. Yet per capita electricity use has decreased by a mere $5 \%$. It may be that as we ramp up the production of renewable energy, this 'decoupling' of electricity use from plant size will continue. Or, like other arguments for energy decoupling, it could be little more than wishful thinking (Fix, 2019b).

\footnotetext{
${ }^{2}$ In 2019, the average US power plant had a nameplate capacity of $123 \mathrm{MW}$. The average solar installation was 11.3 MW. If the US converted to $100 \%$ solar electricity while solar installations remained the same size, the average plant size would decrease by a factor of 11 . According to the trend in Figure 4, electricity use per capita $(E)$ scales with average plant capacity $(C)$ as: $E \propto C^{1.09}$. So as a first approximation, the 10 -fold decrease in plant size would lead to a roughly 10 -fold decrease in per capita electricity use.
} 


\section{Less energy, less hierarchy?}

Suppose that the future is marked by energy degrowth. What does this mean for the structure of our society?

If past trends are any indication, it likely means that the vast corporate hierarchies that define modern capitalism will not last. Of course, I am not the first person to argue that 'degrowth capitalism' is an oxymoron (Foster, 2011). But what is new, in my arguments, is the empirical claim that a degrowth economy will likely have smaller, less hierarchical institutions. If past trends between energy and hierarchy hold, there is no other option.

What exactly this future will look like, though, is anyone's guess. Some sustainability gurus envision a utopia in which humanity has abandoned the myopic power struggles of the past (Weizsäcker, 1997). Fiction writers, in contrast, often imagine a dystopian, neo-feudal future (Atwood, 2006).

Both futures are possible.

For the remainder of this essay, I will explore one dimension of this possible future - income inequality. My argument will appear at first to be contradictory. Hierarchy, I will show, is a major driver of inequality. Individuals with great hierarchical power tend to have great income - on this fact there is little doubt. And since hierarchy drives inequality, it seems like reducing hierarchy (as a consequence of energy degrowth) should also reduce income inequality. But here there is a (seeming) contradiction. Unless hierarchy is all but eradicated, a despotic future marked by vast inequality is a real possibility.

\section{Part 2: Hierarchical inequality}

The emergence of social hierarchy was a Faustian bargain. It likely led to greater levels of social coordination, benefiting groups that adopted it. But hierarchy also burdened humanity with the constant spectre of despotism. Yes, rulers could user their power for the good of society. But they could just as easily enrich themselves, to the detriment of everyone else.

The benefit and cost of hierarchy stem from the same thing - the chain of command. The benefit of the chain of command is that it is a potent tool for coordination. The likely reason? It concentrates decision-making power in the hands of the few, allowing large groups to act cohesively in ways that egalitarian relations do not allow. Yet this concentration of power is also what makes hierarchy pathological. By its nature, the chain of command negates the bottom-up flow of power from subordinates to superiors. Yet this bottom-up 
power is the very thing that stops rulers from using their influence for personal gain.

If I were to give a second simple dimension to human history (the first being energy centralization), it would be this tug-of-war between trying to reap the benefits of hierarchy while also holding rulers to account. On this front, we have certainly made progress. We no longer believe that kings have a divine right to rule. Many societies have some form of democratic government. And the labor movement, when successful, limits the abuse of corporate power. Still, we have a long ways to go.

It is worth noting that this struggle to hold hierarchy to account may extend far beyond humans. The social scientist Herbert Simon argued that hierarchical organization is a fundamental part of all complex systems (Herbert, 1962). Hierarchy is ubiquitous, for instance, within life on earth. Take your body as an example. Your body is not composed of a mass of autonomous cells. Instead, most cells surrender their autonomy to the central nervous system - a hierarchical network of control ending at your brain.

The advantage of this hierarchical organization is that it allows complicated behavior like running - something that would be unthinkable if each cell in the body acted independently. The disadvantage of this centralized control is that if your brain develops a pathology, so does the rest of your body. (During a seizure, for instance, the misfiring of brain cells causes otherwise healthy muscle cells to convulse uncontrollably.) It may be, then, that human societies are trying to solve a problem that our own bodies (and those of all multicellular organisms) have struggled for eons to solve - how to organize in hierarchical groups while suppressing the pathological behavior of those with power (Sober \& Wilson, 1999; Wilson, 2015).

Back to hierarchy in human societies. The despotic tendencies of hierarchy, I will argue, mean that it leads to a ubiquitous social ill — income inequality. One would think, then, that decreasing social hierarchy (through degrowth) would automatically reduce inequality. But as I will show, this intuition is misguided. Unless hierarchy is nearly eradicated, the spectre of (at least some) inequality will likely haunt us.

\section{Hierarchical power and income}

I will begin my inquiry into hierarchical inequality with a simple truism: hierarchy concentrates power. On this virtually everyone agrees. Yet how we should measure this concentration of power is not obvious. The problem is that power 
- the ability to influence others - appears to have many dimensions. The power that a parent wields over a child, for instance, appears different than the power that a slave master wields over a slave. It is unclear how these different forms of power can be reduced to a single dimension.

The confusion about power, I believe, is caused largely because we find it difficult to distinguish power from its perceived legitimacy. That is why the power of a parent appears different than the power of a slave owner. The power of the parent seems legitimate. The power of the slave owner, in contrast, seems illegitimate (to the modern observer, at least). Yet in both cases, power manifests itself as influence over the behaviour of others. The more influence you have, the more powerful you become.

I think this influence can be divided into two dimensions:

1. the strength of a superior's influence over subordinates

2. the number of subordinates a superior controls.

Of these two dimensions of power, the first is the most difficult to measure. The strength of your influence over others depends on the willingness of your subordinates to listen to your command - something that is not easy to quantify. In contrast, measuring the number of people you control is fairly straightforward - especially in a hierarchy. That is because the hierarchical chain of command delineates who is subordinate to whom.

Take, as an example, the hierarchy in Figure 6. In this hierarchy, power flows from the top down. Each superior controls two subordinate, who then control two subordinates of their own ... and so on. This nested chain of command is what defines the hierarchy. From it, we can easily count the number of subordinates controlled by any given person. To do so, we simply follow the chain of command downward. For example, the red individual in Figure 6 controls 2 subordinates directly and 4 subordinates indirectly, for a total of 6 subordinates. We can do the same math for any individual within the hierarchy.

Yes, the strength of this influence over subordinates varies from person to person. But as a first approximation, I propose we ignore this variation. By doing so, we can reduce hierarchical power to a single dimension - the number of subordinates one controls. Here is my formal definition:

$$
\text { hierarchical power }=1+\text { number of subordinates }
$$

I add 1 to the number of subordinates to symbolize that you are never completely powerless. Even if you have no subordinates, you retain control of yourself. 


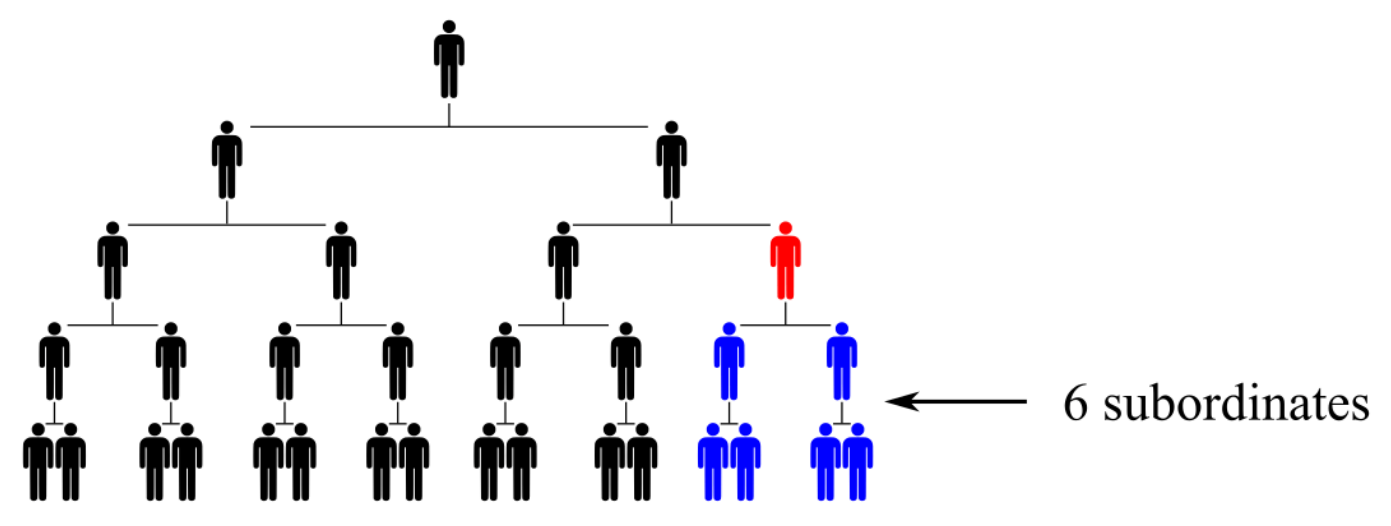

Figure 6: Counting subordinates in a hierarchy

In a hierarchy, the chain of command allows us to count the number of subordinates controlled by a given person. The red individual, for instance, controls 2 subordinates directly and 4 indirectly, for a total of 6 subordinates.

With this definition in hand, the evidence for hierarchical income inequality is straightforward. Within hierarchies, income grows with hierarchical power. Figure 7 displays the evidence. Here the horizontal axis shows the hierarchical power of individuals, defined by Equation (1). The vertical axis shows relative income within the hierarchy (normalized so that the income of bottom-ranked individuals is 1). I have plotted four different sources of data. Green points represent data from six case studies of firm hierarchy (see Fix, 2019d for details). Purple points represent the US military (over the last decade). For both the military and case-study firms, each point represents the average income and hierarchical power of a given rank. Blue points represent a sample of US CEOs. Each point is an individual CEO (see Fix, 2020b for details). Finally, red points show data for the power/income of slave owners in the Cannon's Point Plantation, a 19th-century US slave estate (see Fix, 2019c for details).

The evidence in Figure 7 suggests that across a wide variety of institutions, individual income tends to grow with hierarchical power. For reference, I have plotted the overall trend across all the data. By plotting this trend, I am not supposing that there is a universal law that converts hierarchical power into income. No such law exists. Instead, the trend in Figure 7 is the outcome of complex social dynamics - dynamics that can change over time and space. Nonetheless, the outcome of these dynamics is surprisingly simple. Income tends to be proportional to hierarchical power.

The slope of this power-income relation likely varies between different institutions and different societies. But I propose that its existence is universal. 


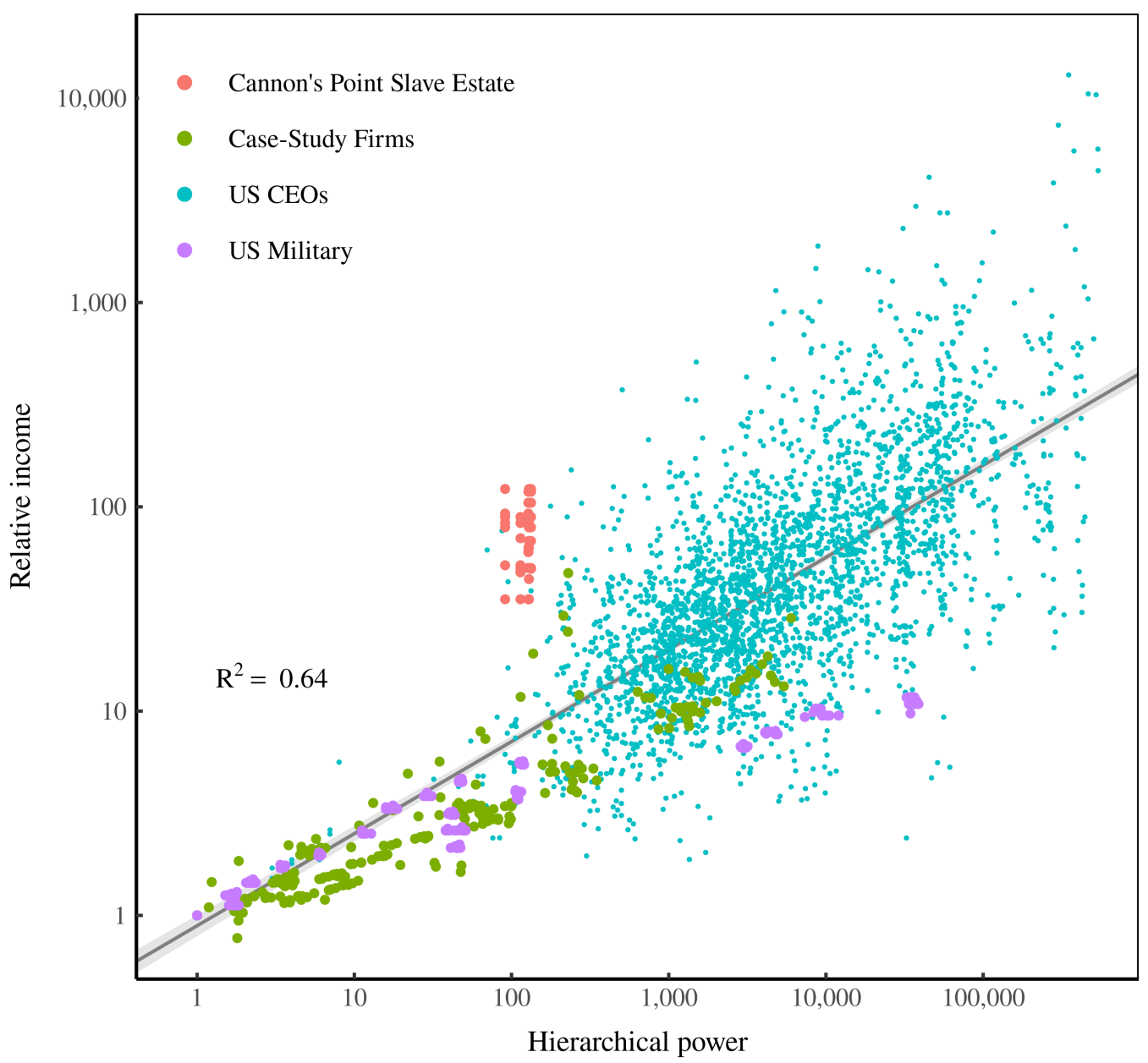

Figure 7: Inside hierarchies, relative income grows with hierarchical power

I plot here the relation between relative income (within a hierarchy) and hierarchical power (the number of subordinates +1 ). In case-study firms and the US military, I measure income relative to the lowest hierarchical rank. For CEOs, I measure income relative to the firm average. In Cannon's Point Plantation, I measure the income of slave owners relative to slaves. Sources and methods.

Whenever there is hierarchy, access to resources likely grows with hierarchical power.

\section{The dynamics of hierarchical inequality}

Supposing that hierarchy is a universal driver of inequality, what does this imply about a degrowth future? If we pursue energy degrowth and small-scale localism, will the resulting reduction in hierarchy reduce inequality? 
To investigate this question, I am going to look at the dynamics of a simple model of hierarchy. The model is based on the seminal work of Herbert Simon (1957) and Harold Lydall (1959). In the 1950s, both scientists independently developed an idealized model of hierarchy. The key to this model is that it simplifies the chain of command to a single dimension - the span of control.

The 'span of control' is the number of direct subordinates controlled by a superior. In the real world, this number varies between different managers. In the Simon-Lydall model, however, we ignore this complexity and instead imagine a hierarchy with a constant span of control. Every superior controls the same number of subordinates. Figure 6, for example, showed a hierarchy with span of control $=2$.

In the Simon-Lydall model, the span of control is a 'free parameter', meaning we can choose the value we like and see what happens. The other free parameter is the size of the hierarchy - the number of members it includes. To the Simon-Lydall model I add a third parameter that I call the 'degree of hierarchical despotism'. This parameter determines the rate at which income grows with hierarchical power.

To summarize, I explore a model of hierarchy with three parameters:

1. The span of control: the number of subordinates controlled by each superior.

2. Hierarchy size: the number of members in the hierarchy.

3. The degree of hierarchical despotism: the rate at which income grows with hierarchical power.

In what follows, I investigate how each of these parameters affects income inequality.

\section{The span of control}

The defining feature of hierarchical organization is the nested chain of command in which each superior controls multiple subordinates. The number of subordinates each superior controls is often called the 'span of control'.

In real-world hierarchies, this span varies both between individuals and between hierarchies. In our model however, we imagine that the span of control is fixed within hierarchies, but free to vary between hierarchies.

Figure 8 shows how the span of control affects the shape of the modeled hierarchy. When the span of control is large, the resulting hierarchy is 'flat', 
A flat hierarchy

( span of control $=5$ )

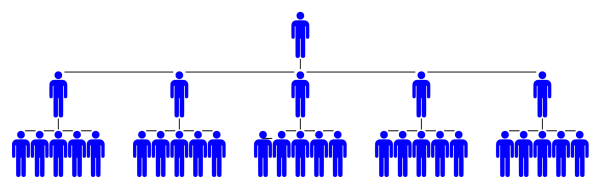

31 members
A steep hierarchy

( span of control $=2$ )

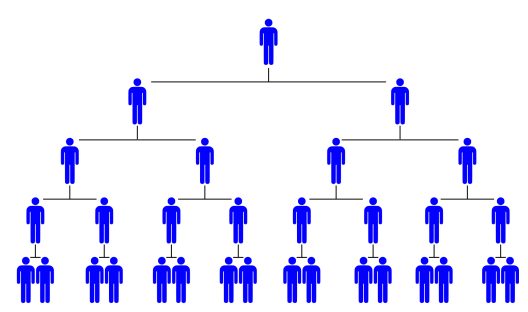

31 members

Figure 8: How the span of control affects the shape of a hierarchy

Here are two different hierarchies, each with 31 members. When the span of control is large (left), the resulting hierarchy is flat. When the span of control is small (right), the hierarchy is steep.

meaning it has relatively few hierarchical ranks. When the span of control is small, the resulting hierarchy is 'steep', meaning it has many hierarchical ranks.

What constitutes a 'large' or 'small' span of control is an empirical question. To get some insight into real-world variation, Figure 9 shows the span of control in different institutions. The span of control appears to vary from a low near 1 to a high near 30. There are, however, clearly differences between institutions.

In Figure 9, 'Firm aggregate studies' are studies that each report the hierarchical structure of multiple firms. The caveat to these studies is that they often look only at the top ranks within each firm (i.e. top executives and their direct subordinates). 'Firm case studies', in contrast, measure the entire hierarchy in a single firm. Only a few such studies exist.

The evidence in Figure 9 suggests that relative to private-sector firms, the US military has a smaller span of control. Perhaps this is because the military requires a chain of command that is tighter than corporate hierarchies? Understanding this variation in the span of control is a fruitful topic for future research.

\section{How the span of control affects the concentration of hierarchical power}

Whether a hierarchy is flat or steep has many practical consequences for the people within it. Here, however, I am interested in only one outcome - how the span of control affects the concentration of hierarchical power.

Recall that for any individual within a hierarchy, we define their hierarchical power as ' $1+$ the number of subordinates'. With this definition, we can calculate 


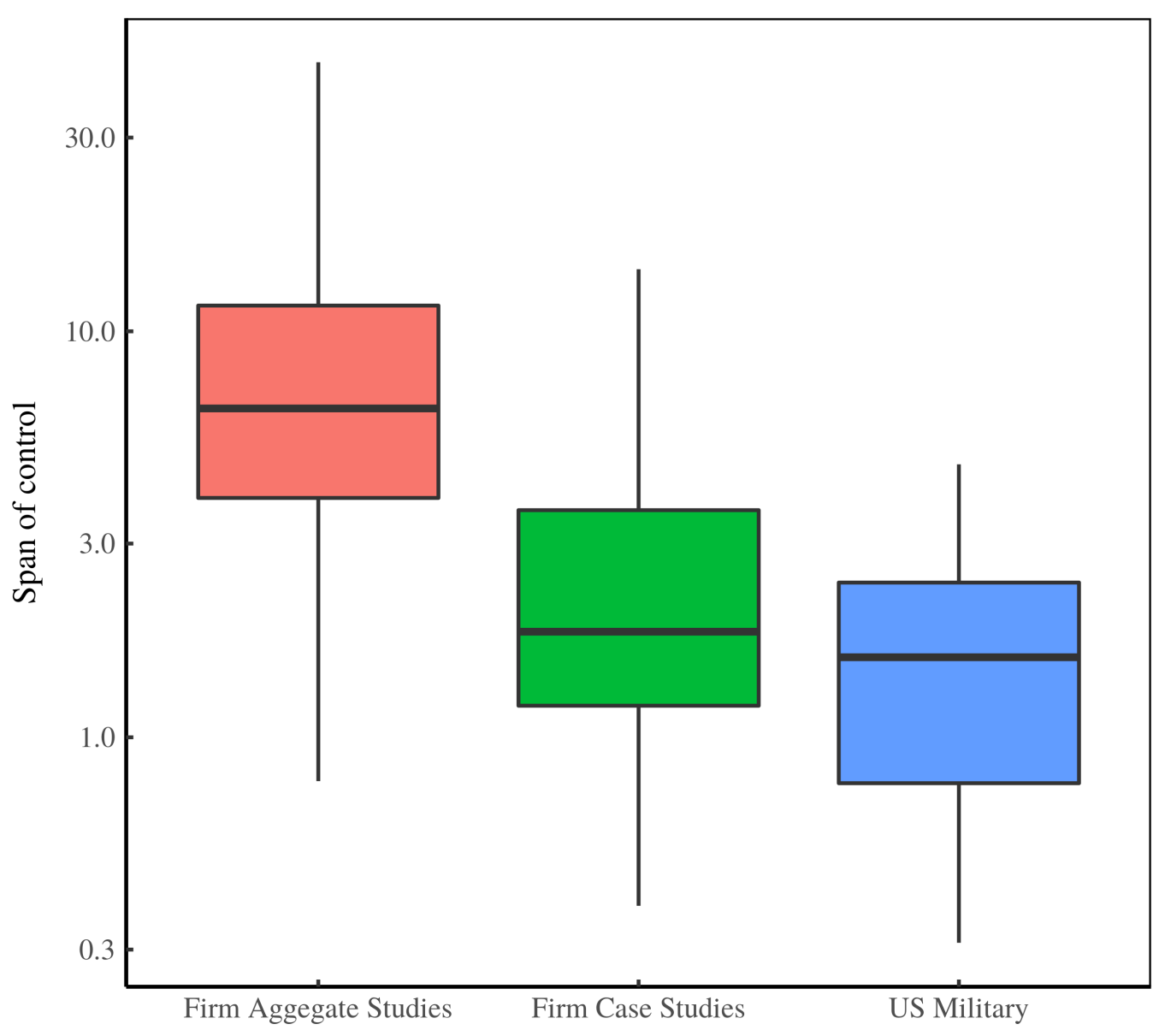

Figure 9: The span of control in real-world institutions

Boxplots show the distribution of the span of control within different types of institutions. Note the log scale on the vertical axis. 'Firm aggregate studies' report the hierarchical structure of multiple firms. 'Firm case studies' measure the hierarchy in a single firm. Data for the US military covers roughly the last two decades. Sources and methods.

the hierarchical power of every individual within the hierarchy. The result is a distribution of hierarchical power across all individuals. The reason this distribution is important is because we expect it to affect income inequality. If income is proportional to hierarchical power, then as power becomes more concentrated, so too will income. To measure the concentration of hierarchical power, I will use the Gini index (a common measure of inequality).

Back to the span of control. Because the span of control affects the shape of the chain of command, it affects the distribution of hierarchical power within a hierarchy. When the span of control is small, it produces a 'steep' hierarchy 
in which power is more concentrated. Conversely, when the span of control is large, it produces a 'flat' hierarchy in which power is more diffuse.

The exact relation between the span of control and the concentration of hierarchical power depends on the size of the hierarchy. But to see the general form of this relation, we can pick an arbitrarily-sized hierarchy and then vary the span of control. Figure 10 shows the result. Here I model a large hierarchy with 100,000 members (about the size of present-day Microsoft). The horizontal axis shows the span of control in different model iterations. (Note the log scale.) The vertical axis shows the resulting concentration of hierarchical power, as measured by the Gini index. The general trend is clear. As the span of control increases, hierarchical power becomes less concentrated.

A few things to note about the Figure 10 results. First, the trend in the concentration of hierarchical power is not smooth, but instead has a saw-tooth shape. This is a characteristic feature of hierarchy. As the span of control increases, each drop in the sawtooth corresponds to the removal of a hierarchical rank. When a rank disappears, the concentration of hierarchical power immediately decreases.

Second, note that I have modeled a span of control that varies over an enormous range - from a low of 1 to a high of 1000. For real-world hierarchies, the upper reaches of this range are not plausible. If we believe Robin Dunbar's social-brain hypothesis (Dunbar, 2009), then the span of control of human hierarchies cannot greatly exceed 150 ('Dunbar's number'). And even if we do not accept Dunbar's theory, there is little empirical evidence to suggest that the span of control can get above 100. The empirical range for the span of control (the shaded region in Fig. 10) appears to be between 1 and 50 .

Over this realistic range, the span of control does affect the concentration of hierarchical power ... but not greatly. No matter how large it gets, the span of control cannot produce zero concentration of hierarchical power. This fact stems from a basic feature of hierarchy, together with how I have defined hierarchical power. In the limit that the span of control gets very large, the hierarchy will reduce to two ranks. There will be one ruler who controls everyone else. If there are $n$ people in the hierarchy, the ruler has hierarchical power $n$, while $n-1$ people have hierarchical power of 1 . I leave it to the reader to show that this corresponds to a Gini index of 0.5. 


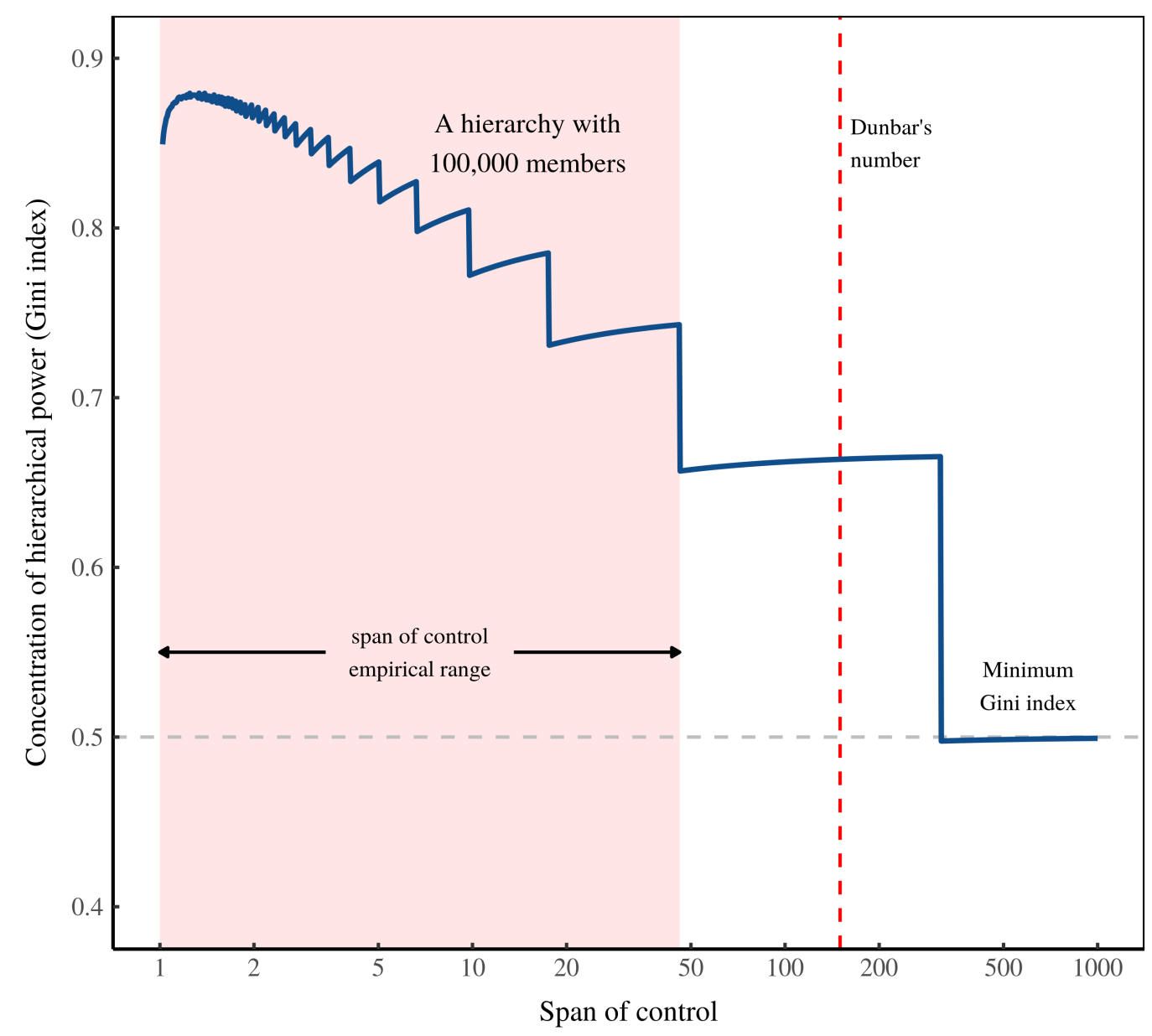

Figure 10: How the span of control affects the concentration of hierarchical power

The horizontal axis shows the span of control in a model hierarchy with 100,000 members. The vertical axis shows the resulting concentration of hierarchical power, as measured by the Gini index. The shaded region represents the span-of-control range found in real-world institutions (Fig. 9). The dashed vertical line shows Dunbar's number a span of control of 150. The dashed horizontal line shows the minimum concentration of hierarchical power, which occurs when there are only two ranks in the hierarchy. Sources and methods.

\section{Hierarchy size}

Unlike the span of control, which varies over little more than an order of magnitude, the size of a hierarchy can vary by a factor of several million. On the small end, a hierarchy can consist of just two people - a superior and subordinate. On the large end, a hierarchy can have millions of members, like modern-day 


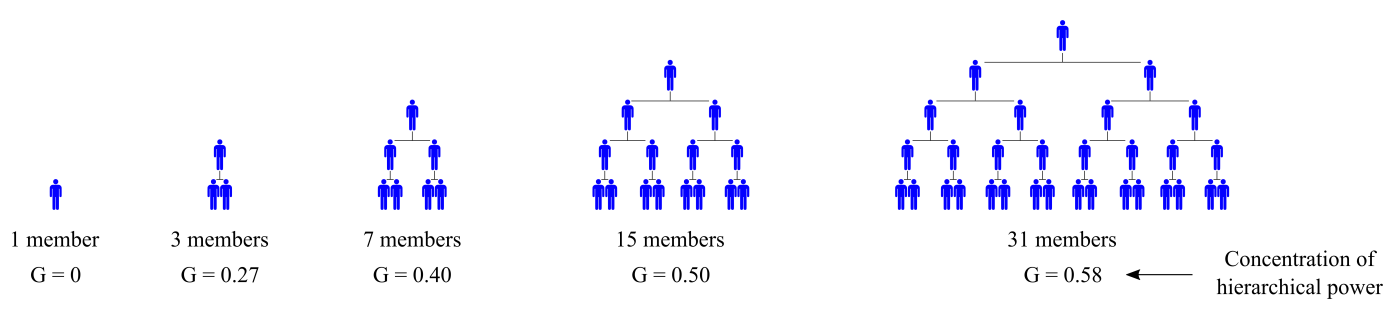

Figure 11: How hierarchy size affects the concentration of hierarchical power

From left to right, a hierarchy (with span of control $=2$ ) grows from 1 to 31 members. Below each configuration, I show the concentration of hierarchical power, as measured by the Gini index $(G)$.

Walmart and the US federal government.

The size of a hierarchy affects the concentration of hierarchical power. Small hierarchies have relatively few ranks, so hierarchical power is diffuse. Large hierarchies have many ranks, allowing elite individuals to wield immense power. The result is that hierarchical power becomes more concentrated as hierarchies grow bigger.

Figure 11 shows an example of this process. From left to right, I show a hierarchy growing larger. Below each configuration, I label the concentration of hierarchical power, as measured by the Gini index (G). On the left, we start with one person who is autonomous. Since there is no hierarchy, there is zero concentration of hierarchical power. Moving right, we add two more members to the group and suddenly a hierarchy emerges. With it, hierarchical power immediately goes from zero concentration to having a Gini index of 0.25 . As the hierarchy grows larger still, hierarchical power continues to become more concentrated. Note, however, that the pace of this concentration slows. As the hierarchy (nearly) doubles from 15 to 31 members, hierarchical power becomes only slightly more concentrated - changing from a Gini index of 0.44 to a Gini index of 0.51 .

From the example in Figure 11 we can see two things. First, hierarchical power tends to become more concentrated as hierarchies get larger. Second, the growth of this concentration is non-linear. The cause of this non-linearity is the structure of hierarchy itself. What concentrates hierarchical power is not the addition of new members per se, but rather the addition of new hierarchical ranks.

New ranks, it turns out, come at a logarithmic pace as the hierarchy grows. You can see this fact in Figure 11. The size $(S)$ of each hierarchy is $S=2^{n}-1$, 
where $n$ is the number of hierarchical ranks. Solving for $n$, we find that the number of ranks is proportional to $\log (S-1)$. The result of this logarithmic addition of new ranks (as the hierarchy grows) is that the concentration of hierarchical power grows rapidly at first, but then levels off.

We can see this non-linear behavior more formally in Figure 12. Here I show a model hierarchy that starts with 1 member and then grows until it reach 10 million members. I plot this size on the horizontal axis. (Note the log scale). On the vertical axis, I show the corresponding concentration of hierarchical power. As the hierarchy grows from a single member to a few dozen, the concentration of hierarchical power explodes. But as the hierarchy continues to grow, the concentration of hierarchical power plateaus. The location of this plateau is a function of the span of control, which I have chosen here to be 3. (When the span of control is larger, the plateau in the concentration of hierarchical power occurs at a lower Gini index.)

Note, in Figure 12, that there is a step-like pattern to how the concentration of hierarchical power changes with the hierarchy's size. From left to right, each step corresponds to the addition of a new hierarchical rank. The consequence of each new rank is a sudden jump in hierarchical power concentration.

Let's move on now to the inset panel in Figure 12, which shows an unintuitive feature of hierarchy. I have plotted here the relative hierarchical power of the top-ranking individual in the hierarchy. Think of this metric like the familiar CEO pay ratio, which measures the pay of a CEO relative to the average employee's pay. In the inset panel in Figure 12, I plot the same thing ... except I substitute pay with hierarchical power. The result shows the hierarchical power of the ruler relative to the average hierarchical power of all members of the hierarchy. What we find is that this relative power increases perpetually as the hierarchy grows larger. What is unintuitive is that this perpetual growth of the ruler's power does not translate into the perpetual concentration of hierarchical power (Fig. 12, main panel). How can this be?

The reason has to do with an interplay between the ruler's hierarchical power and their rarity. As a hierarchy gets larger, the ruler continuously accumulates hierarchical power. But at the same time, the ruler also grows rarer. Here is an example. In a hierarchy consisting of two members - a superior and a subordinate - the ruler constitutes half the population. But in a hierarchy with millions of members, the lone ruler constitutes a minuscule portion of the hierarchy's population.

When we measure inequality using the Gini index, we take into account this rarity. The result is that at some point, the ruler's rarity trumps their growing 


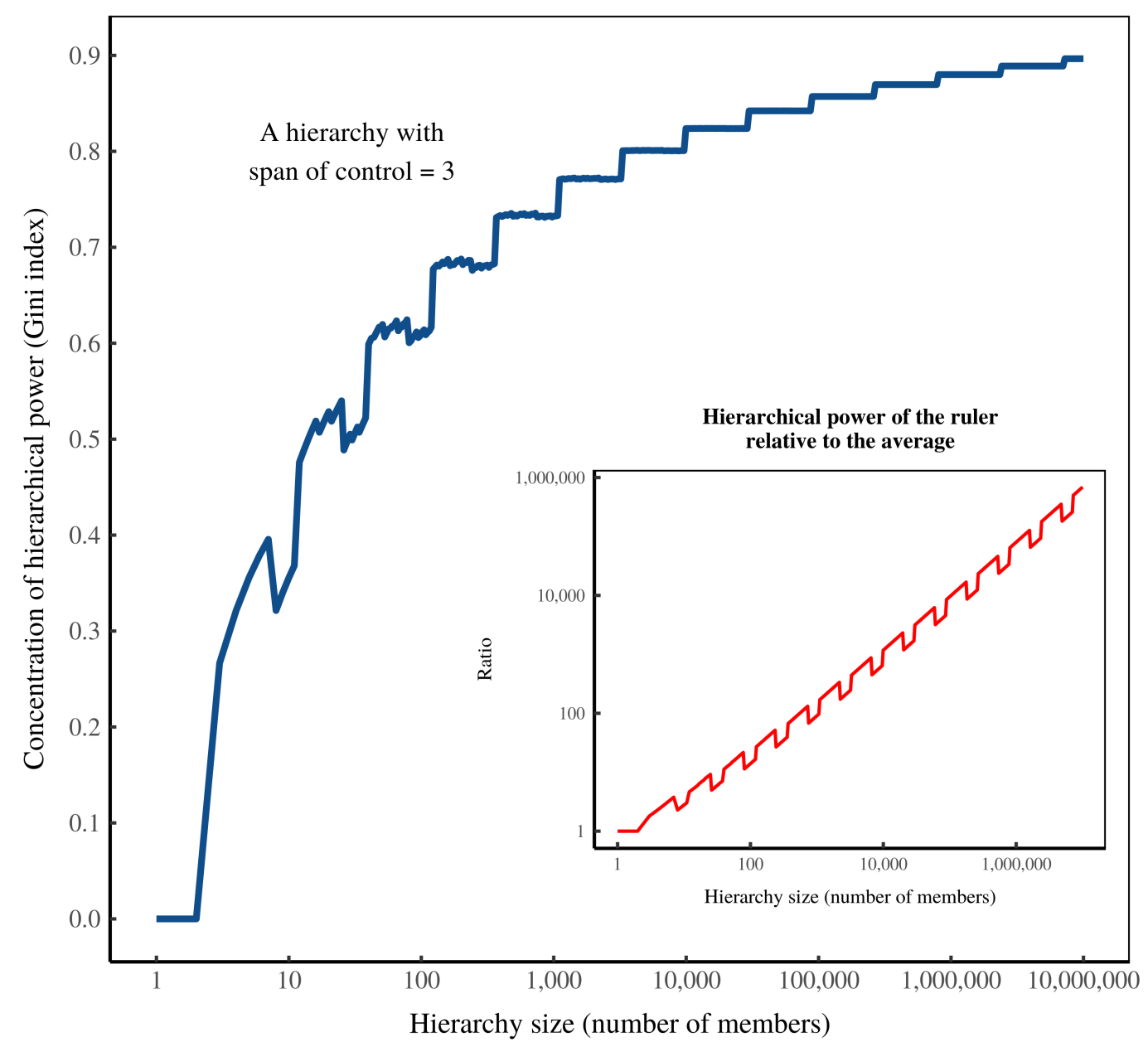

Figure 12: How the size of a hierarchy affects the concentration of hierarchical power

I show here a modeled hierarchy with a span of control of 3 . The vertical axis shows the hierarchy's size, as measured by the number of members. In the main panel, the vertical axis shows the resulting concentration of hierarchical power. The inset panel shows the ratio of the hierarchical power of the top-ranking individual (the ruler) relative to the average hierarchical power of all members of the hierarchy. Sources and methods.

hierarchical power. When this happens the concentration of hierarchical power plateaus. But when we measure the ruler's relative power, we ignore their rarity. So as the hierarchy grows, the relative power of the ruler expands without end.

This feature of hierarchy, incidentally, is why the CEO pay ratio does not necessarily indicate income inequality within a firm. The pay ratio tends to grow with hierarchy size - a simple consequence of income scaling with hierarchical power (Fig. 7). But when we measure income inequality using the Gini index, 
we take into account the rarity of the CEO. Counter-intuitively, then, firms with a small CEO pay ratio can have significant income inequality. And firms with a large CEO pay ratio can have relatively little income inequality. It all depends on the hierarchy's size.

Back to the dynamics of hierarchical-power concentration. What is important is that virtually all of the increases in hierarchical power concentration occur as the hierarchy grows from a handful of members to a few thousand. Beyond this size, changes in the concentration of hierarchical power are minimal. As I will discuss shortly, this behavior has important implications for energy degrowth.

(A final note on Fig. 12. The trend in the inset panel has a sawtooth-shape that needs explanation. As the hierarchy grows, new ranks occasionally get added. When this happens, the ruler's hierarchical power suddenly jumps. But there are also sudden drops in the ruler's power. This behavior is an artifact of how I have chosen to construct the hierarchy. For certain configurations, the top hierarchical rank will have several members. When this happens, the hierarchy suddenly has several rulers, and so their individual hierarchical power drops. If instead we required that the top rank have only one member, this reverse saw-tooth behavior would disappear.)

\section{Hierarchical despotism}

I turn now to the third (and final) feature of hierarchy that I consider here - the degree of hierarchical despotism. This feature is different than the two considered previously in that it does not affect the chain of command.

Recall that the span of control changes the 'shape' of the chain of command by making the hierarchy steep or flat. The size of the hierarchy changes the number of ranks in the chain of command. The 'degree of hierarchical despotism', in contrast, does not affect the chain of command. Instead, it affects how income grows with hierarchical power.

To understand this parameter, let's begin with some simple math. The evidence in Figure 7 suggested that within hierarchies, income tends to grow with hierarchical power. We can model this relation as:

$$
\text { income } \propto \text { (hierarchical power })^{D}
$$

In this equation, the exponent $D$ determines the rate at which income grows with hierarchical power. The larger the value of $D$, the more rapidly income in- 
creases as you accumulate power. Because $D$ has provocative real-world significance, I give it a provocative name. I call it the degree of hierarchical despotism.

I use the word 'despotism' because it connotes the abuse of power. I have argued that the benefit of hierarchical organization is group coordination. The cost, however, is that hierarchy lends itself to the abuse of power. This despotism can have many dimensions (violence, oppression, verbal abuse, etc.). But here I will consider only one - the hoarding of resources. The more a ruler uses their power to hoard resources, the more despotic they become. The parameter $D$ quantifies this despotism.

Figure 13 illustrates how the 'degree of despotism' affects income within a hierarchy. The horizontal axis indicates hierarchical power. The vertical axis indicates relative income. Grey dots show empirical data, replotted from Figure 7. Over top of this empirical data are colored lines which show how income scales with hierarchical power for different degrees of hierarchical despotism, $D$. The larger the value of $D$, the more rapidly income grows with hierarchical power.

Note that Figure 13 uses a log scale on both axes. This is useful for showing data that varies across many orders of magnitude. However, it downplays the extreme effect that hierarchical despotism has on income. To understand the magnitude of the effect, consider a ruler who commands 1 million subordinates. If the degree of hierarchical despotism is $D=0.1$, our ruler will earn about 16 times the income of a bottom-ranked individual. But if hierarchical despotism increases to $D=1$, the same ruler will earn 1 million times that of a bottomranked individual.

Because it is just a model parameter, the degree of hierarchical despotism can in principle have any value. It could be 0 , meaning there are no returns to hierarchical power. It could even be negative, meaning your income would decrease as you accumulate power. In practice, however, the degree of hierarchical despotism is constrained to a fairly narrow range.

We can see this fact by estimating the degree of hierarchical despotism $(D)$ in real-world hierarchies. Figure 14 shows such estimates for various institutions. It appears that in the real world, hierarchical despotism varies from a low near $D=0.1$ to a high slightly above $D=1$.

The evidence in Figure 14 suggests that the degree of hierarchical despotism varies between different types of institutions. The US military, for instance, appears to be on the low end of hierarchical despotism. Yes, the military may have a strict chain of command. But pay is surprisingly equal. Top generals command 


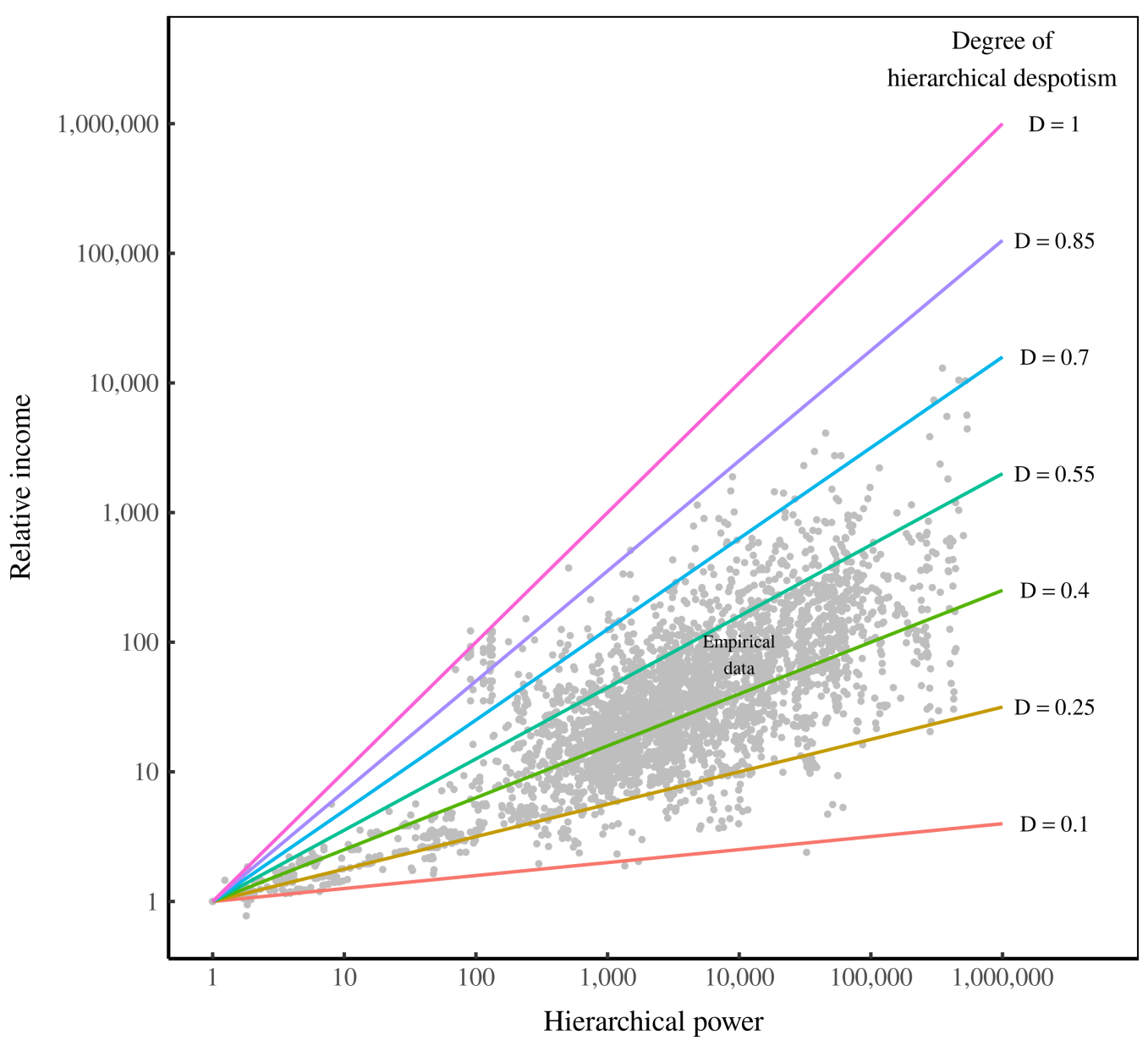

Figure 13: How the degree of hierarchical despotism affects income

I plot here relative income (in a hierarchy) against hierarchical power. Grey points represent empirical data, replotted from Fig. 7. Colored lines show how income grows with hierarchical power for different values of $D$ - the degree of hierarchical despotism. Sources and methods.

hundreds of thousands of subordinates, yet earn only about 10 times the income of bottom-ranked soldiers. That corresponds to $D \approx 0.2$.

On the opposite end of the despotism spectrum is Cannon's Point Plantation, a 19th-century US slave estate documented by John Otto (1984). Otto reports the number of slaves in the plantation, the expenses spent on slaves, as well as the owner's profit. I have used these values to make a (very) rough estimate of the degree of hierarchical despotism in the estate. (See Fix, 2019c for details.) Unsurprisingly, the slave estate appears to be highly despotic. The plantation owner had roughly one hundred slaves, and typically earned about 100 times more in profits than he expended per slave. That corresponds to a degree of 


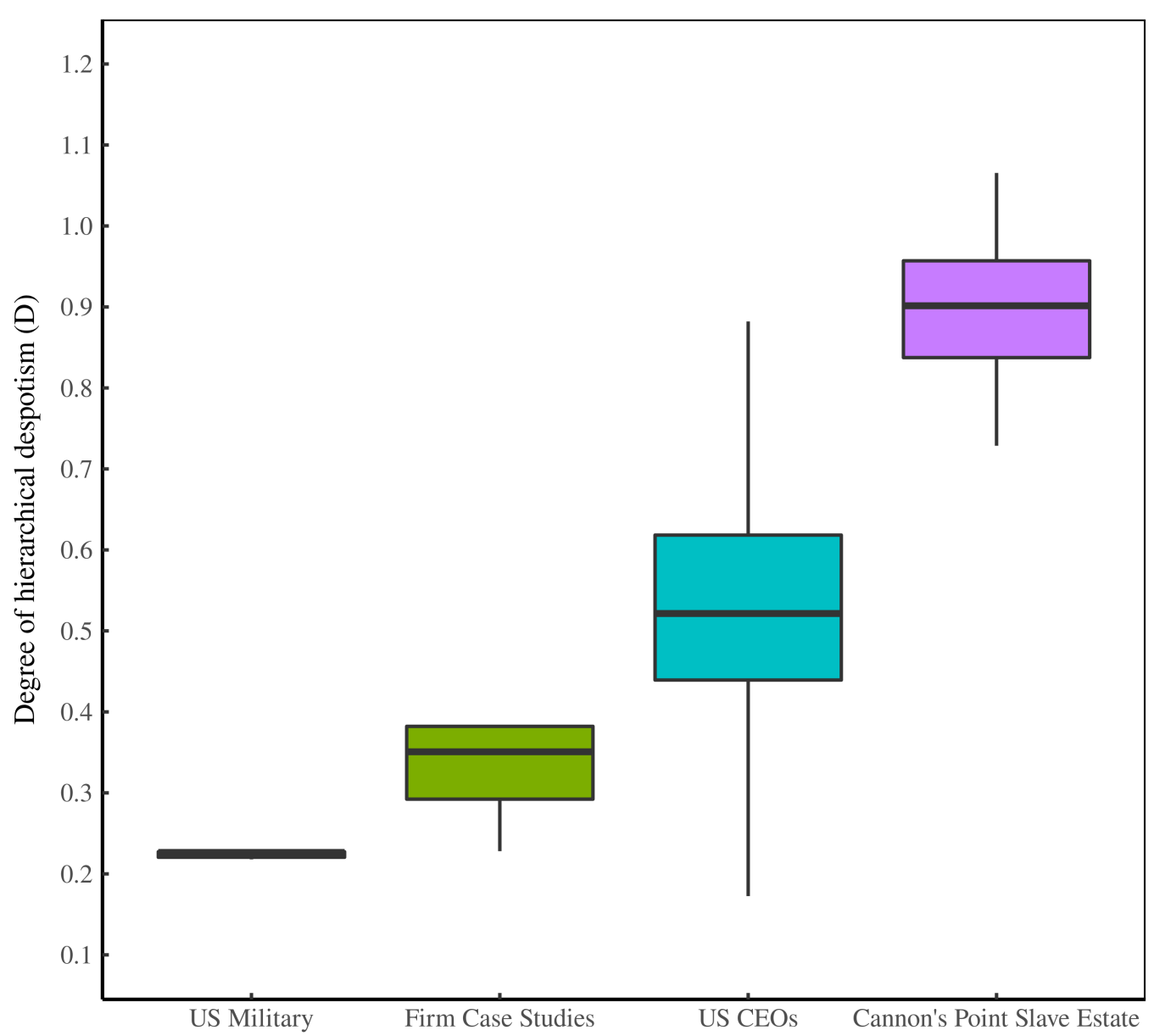

Figure 14: The degree of hierarchical despotism in real-world hierarchies

Boxplots show the range of estimates for the degree of hierarchical despotism $(D)$ in various institutions. Data for the US military covers roughly the last decade. 'Firm case studies' represent a handful of studies of the hierarchy within individual firms. 'US CEOs' represents the value of $D$ inferred from CEO pay. 'Cannon's Point' shows the value of $D$ inferred from the income of the owner of a 19th-century US slave estate. Sources and methods.

hierarchical despotism of $D \approx 1$.

Modern business firms appear to be between the extreme of the US military and Cannon's Point Plantation. In Figure 14, I show estimates of $D$ within case studies of firm hierarchy. I also use the income of US CEOs to estimate the degree of hierarchical despotism in their corresponding firms. Both estimates occupy the middle ground of hierarchical despotism.

From the evidence in Figure 14, I assume that in real-world hierarchies the degree of hierarchical despotism varies from a low of $D=0.1$ to a high of $D=$ 


\section{1 .}

\section{How the degree of hierarchical despotism affects income inequality}

How and why hierarchical despotism varies between institutions remains poorly understood. It is easy, however, to understand the effect that this despotism has on income inequality. To do so, we return to our model of hierarchy.

The effect that hierarchical despotism has on inequality depends on both the size of the hierarchy and the span of control. But we can get a general sense for this effect by picking arbitrary values for the hierarchy size and span of control. Here I will model a hierarchy containing 100,000 members with a span of control of 3. Figure 15 shows how the degree of hierarchical despotism affects income inequality within the hierarchy.

It is clear, from this model, that hierarchical despotism strongly affects income inequality. To get a sense for the size of this effect, I have plotted in Figure 15 the range of income inequality found in modern societies. On the low end was the Czech Republic in 1992, with a Gini index of 0.21. On the high end was Malawi in 1997, with a Gini index of 0.66. (Data is from the World Bank.) This comparison between the model and real-world societies is not meant to be rigorous. (The model consists of a single hierarchy, real-world societies consist of many hierarchies.) My point is to show that when the degree of hierarchical despotism varies across a realistic range in a single hierarchy, it can reproduce the full range of income inequality found in modern societies.

\section{Decomposing hierarchical inequality}

Having explored the three features of hierarchy (the span of control, size, and degree of despotism), it is time to put everything together. I now compare each feature's effect on income inequality.

As I have stressed previously, the three features of hierarchy work together to produce income inequality. As such, there is no unique 'effect size' for any given feature. Nevertheless, each feature works distinctively enough that we can see the general form of its effect by picking arbitrary (but realistic) values for the other parameters.

Figure 16 shows the results of such a comparison. I plot here the income inequality within a single hierarchy that has the following default values:

- span of control = 3

- hierarchical despotism $D=0.5$ 


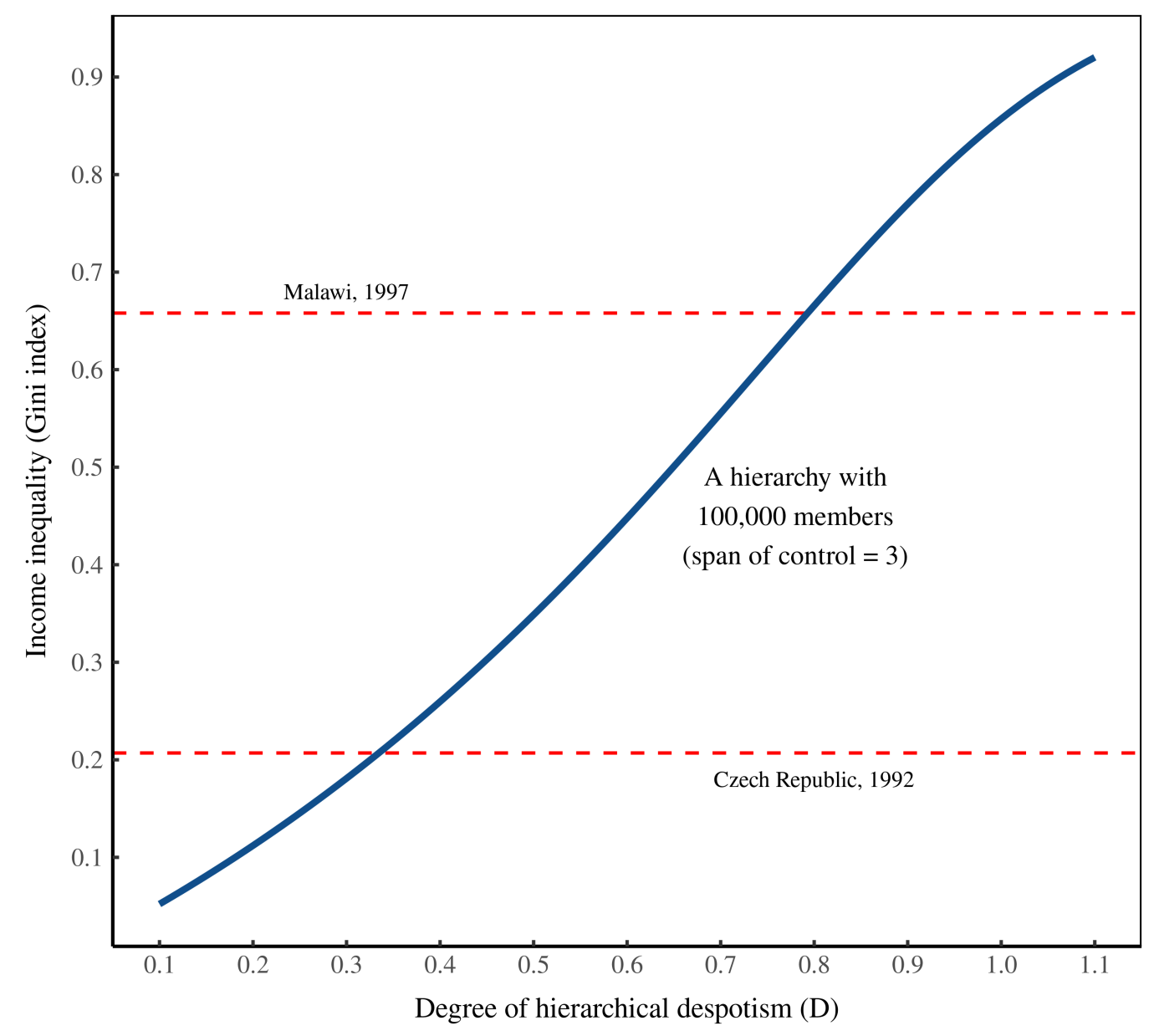

Figure 15: How the degree of hierarchical despotism affects income inequality in a model hierarchy

I plot here the results of a model hierarchy containing 100,000 members with a span of control of 3. The horizontal axis shows the degree of hierarchical despotism $(D)$ - the rate at which income scales with hierarchical power. The vertical axis shows the resulting concentration of income, as measured by the Gini index. For reference, the dashed horizontal lines show the lowest and highest Gini indexes (for countries) recorded in the World Bank database. Sources and methods.

- size $=100,000$ members

Each curve in Figure 16 shows the effect of varying one of these default values. I plot the resulting income inequality on the vertical axis. The horizontal axis shows the parameter variation, plotted on a normalized (linear) scale that varies from 0 to 1 . The point of this analysis is to highlight the differing effect that each feature of hierarchy has on income inequality.

Let's start with the span of control. As the span of control grows larger, 


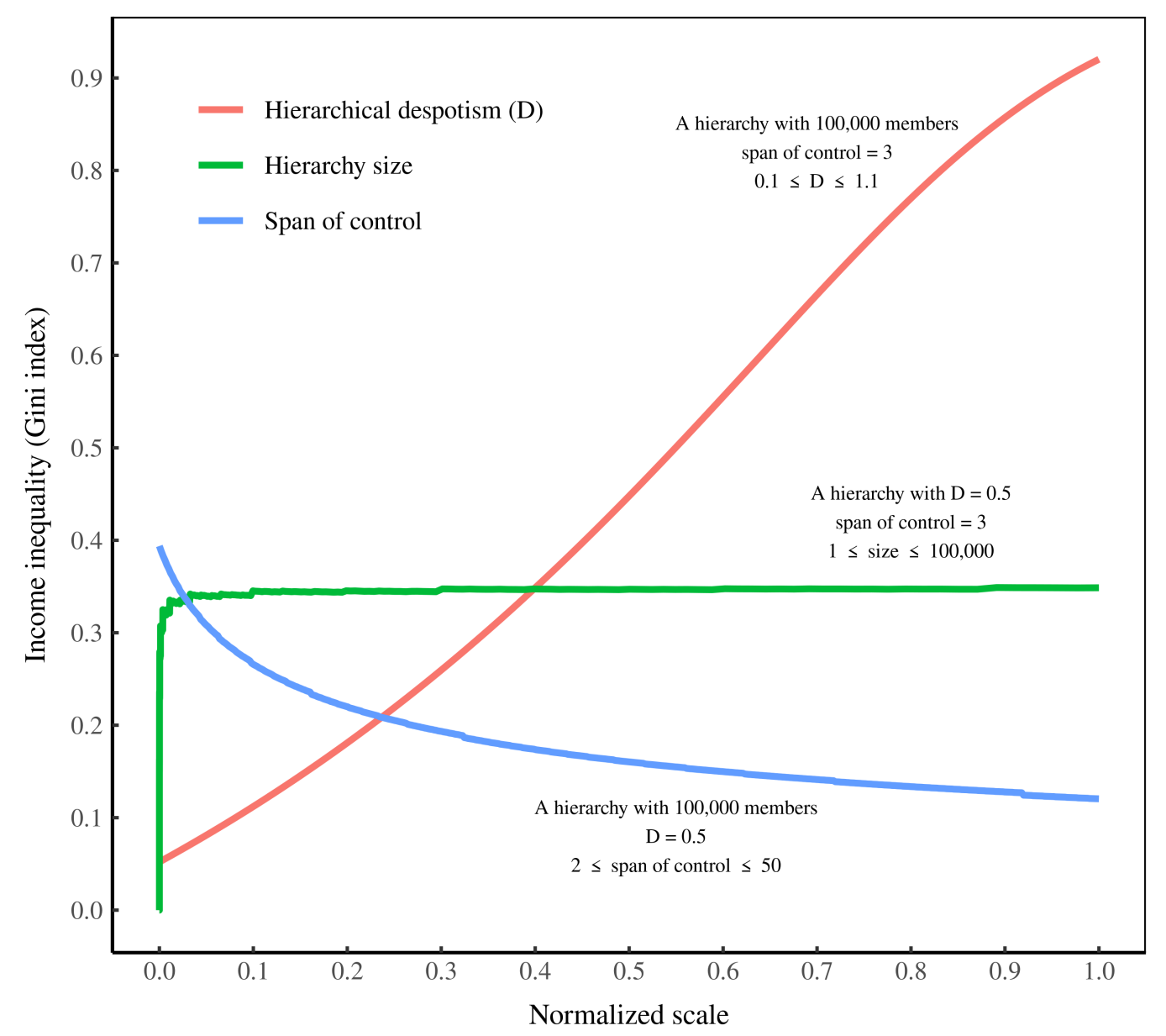

Figure 16: How hierarchical despotism, hierarchy size and the span of control affect income inequality

I plot here the income inequality within a single hierarchy that has the following default values: span of control $=3$, hierarchical despotism $D=0.5$, size $=100,000$ members. Each curve shows the effect of varying *one* of these default values. The horizontal axis shows the parameter variation, plotted on a normalized (linear) scale that varies from 0 to 1 . The vertical axis shows the resulting income inequality, measured by the Gini index. Sources and methods.

income inequality tends to decrease. This occurs because as the span increases, the hierarchy becomes flatter. The result is that hierarchical power becomes less concentrated, and so too does income. Note, however, that the effect of increasing the span of control is non-linear. No matter how large the span of control gets, it cannot remove inequality completely.

What about hierarchy size? Like the span of control, varying a hierarchy's size has a non-linear effect on income inequality. Except with hierarchy size, the 
effect is so abrupt that it seems (on a linear scale) almost like a step function. Depending on the size of the hierarchy, either there is considerable inequality ... or there is none. The model suggests that to significantly reduce inequality in a hierarchy with 100,000 members, we would have to shrink its size by about $99 \%$.

Finally, let's look at the degree of hierarchical despotism. It is clear, from Figure 16, the degree of hierarchical despotism has the strongest effect on income inequality. In terms of total variation in inequality, no other feature of hierarchy comes close to producing the same effect. And unlike the other features of hierarchy, note that varying hierarchical despotism has a roughly linear effect on inequality. This indicates that no matter the current degree of hierarchical despotism, reducing this despotism will always reduce income inequality.

Although the effect of each feature of hierarchy depends jointly on all three parameters, one thing seems clear. Over the range observed in real-world hierarchies, the degree of hierarchical despotism has the strongest effect on income inequality. This result has important implications for how we can achieve equitable degrowth.

\section{Part 3: Pathways to equitable degrowth}

Let's return now to the big picture of sustainability. Virtually all sustainability researchers agree that we (humanity) need to curb our fossil fuel habit. The obvious solution is to transition to renewable energy sources. The question is can we achieve this renewable transition while keeping our society in its current form? The answer, I have argued, may be no.

Here is why. Let's start with the level of energy consumption. Some scientists think that renewable energy can meet current energy demands. ${ }^{3}$ There are, however, reasons to be skeptical of this claim. That is because renewable energy sources are fundamentally different than fossil fuels. For one thing, renewables tends to have lower 'energy return on energy investment' than fossil fuels. ${ }^{4}$ For another, renewable electricity generation tends to be less centralized than fossil fuel (Fig. 5).

\footnotetext{
${ }^{3}$ See for instance Jacobson et al. (2015) and Jacobson et al. (2017). The caveat here is that Jacobson and colleagues assume that end-use energy will remain stable. But they assume that efficiency gains will reduce the demand for primary energy.

${ }^{4}$ See Hall, Lambert, \& Balogh (2014). But note that there is controversy about the EROI of solar PV. See Bhandari, Collier, Ellingson, \& Apul (2015) and Palmer \& Floyd (2017).
} 
This small-scale nature of renewable energy is often touted as an advantage. And it may be one ... assuming sustainability is the only goal. However, if the goal is also to maintain current rates of energy use, then there may be a problem. That's because the evidence suggests that energy use scales with energy centralization (Fig. 4). So if in the future, electricity generation becomes less centralized, the result may be inevitable energy degrowth.

What does this energy degrowth imply for the structure of society? Past trends again suggest an answer. Historically, the growth of energy consumption is associated with the growth of hierarchy (Figs 1-3). If the future is marked by energy degrowth, it seems plausible that the historical trend may simply reverse. If so, a degrowth future will be marked by less social hierarchy.

Taking this thought experiment further, we can ask — what does the reduction of hierarchy imply for income inequality? On that front, it seems (at first glance) like degrowth might automatically reduce inequality. That is because within hierarchies, income tends to grow with hierarchical power (Fig. 7). If energy degrowth reduces the concentration of hierarchical power (by reducing the size of hierarchies), it seems plausible that it might automatically lead to more equality. Looking more deeply at the dynamics of hierarchy, however, splashes cold water on this idea.

The problem, according to our model, is that hierarchy size has an extremely non-linear effect on inequality (Fig. 16). To understand this non-linear effect, imagine taking a large hierarchy like Walmart and shrinking it until income inequality is significantly reduced. Our model suggests that virtually all of the inequality reduction comes in the last mile, after having shrunk Walmart by about $99 \%$. That is not to say we could not achieve this feat. But the effect on society would be drastic.

One way to think about this hypothetical future (marked by smaller hierarchies) is to look into our distant past. A remarkable feature of human history is that once inequality emerged, it never went away (Price \& Feinman, 1995, 2010). This fact, I believe, can be attributed to the emergence of hierarchy. For the vast majority of human history, there simply was no hierarchy to speak of. If modern hunter-gathers are any indication, early human groups were fiercely egalitarian and shunned anything like a chain of command (Boehm, 2009; Boehm et al., 1993). However, for reasons that we poorly understand, the rise of civilization saw people suddenly organize in hierarchies. And with these hierarchies came inequality. Once this happened, 'civilized' humans never returned to the egalitarian ways of their ancestors. Why?

A plausible reason was that some form of hierarchy was required to meet the 
energy needs of civilization. As such, civilizations faced a 'choice'. Either keep the hierarchy that was needed to support civilization, and live with the resulting inequality. Or achieve equality by getting rid of hierarchy, but by so doing, undermine the energetic basis of civilization itself. Assuming my reasoning is correct, the civilizations that survived opted for the first choice.

Framed this way, it seems unlikely that energy degrowth will significantly reduce inequality. Yes, using less energy may cause hierarchies to shrink. But unless we are willing to return to subsistence levels of energy use, the historical evidence suggests that we will be burdened with at least some form of hierarchy that is capable of generating significant inequality (Fix, 2019c).

That said, there are steps that we can take to live with social hierarchy but still mitigate income inequality. The solution, pointed to by our model, is to limit the rate at which income grows with hierarchical power - something I call the degree of hierarchical despotism (Fig. 16). When the degree of hierarchical despotism is low (as in the US military), hierarchies can be large and yet have relatively little income inequality. But when the degree of hierarchical despotism is high (as in slave estates), even small hierarchies can scrape the limits of inequality.

\section{Limiting hierarchical despotism}

If the key to achieving equitable degrowth is to limit hierarchical despotism, this begs a question. How do we do that?

The short answer is that we do not know. Despite the ubiquity of social hierarchy, we know little about how and why pay practices vary between hierarchies. As such, there is not enough evidence to make definitive claims about how to reduce hierarchical despotism. The long answer, however, is that there are hints about what we might do. I propose that a general way to limit hierarchical despotism is to impose accountability on those with power.

The seeds of despotism, I believe, lie in the hierarchical chain of command itself. In pure form, the chain of command imposes top-down power that is absolute. Superiors command ... subordinates obey. This asymmetry, I propose, is the basis of all tyranny. The way to limit abuses of power, then, is to dampen the chain of command by allowing subordinates to influence the behavior of superiors. This is the principle of bottom-up accountability. I propose that a hierarchy will be despotic (in terms of income distribution) to the degree that it lacks accountability.

What is the evidence for this principle? A good place to start is to look at 
hunter-gatherer societies that strictly limit the accumulation of power. The anthropologist Christopher Boehm (1993) argues that such societies are not 'innately' egalitarian, but rather, have developed a culture that enforces equality. Boehm calls this culture 'reverse dominance'. If an individual became too powerful, Boehm observed, less dominant individuals would gang up to knock the would-be ruler down a notch (sometimes by killing them). This bottom-up dominance is a form of what we today call 'accountability'. It holds the powerful in check.

Looking at modern societies, there is evidence for the same principle. When hierarchies are held in check by some form of bottom-up accountability, hierarchical despotism seems to be reduced. The US military, for instance, has remarkably equal pay among its members (Fig. 14). One might suppose that this equality is a general feature of all armies. But I doubt it. Historically, militaries were headed not by civilians, but by despotic kings (Turchin, 2016). Even today militaries run some governments, often with despotic results.

No, the equal pay found in the US military is likely not a general feature of armies, but rather a feature of accountability. Members of the US military have strict pay limits dictated by the Executive Schedule (set out in U.S.C. §§ 53115318). This constraint is not something that the military has adopted voluntarily. The executive schedule has been imposed by the federal government. The reason is simple. The US government is accountable to voters, and these voters do not take kindly to public officials enriching themselves from the public purse. And so there is constant pressure to limit the pay of top government officials, both civilian and military. The result is that within the US government, there is little hierarchical despotism (as I have defined it).

Accountability also seems to limit pay inequality in the private sector. Paul Joskow and colleagues have found that executive pay in US electric-utilities firms is consistently lower than in other sectors (P. L. Joskow, Rose, \& Wolfram, 1996; P. Joskow, Rose, Shepard, Meyer, \& Peltzman, 1993). The reason, they suspect, is that the utilities sector is tightly regulated by government. This accountability seems to stop top executives from using their power to enrich themselves. There is also evidence that unions have the same effect. The presence of unions a form of bottom-up accountability - tends to limit executive pay (DiNardo, Hallock, \& Pischke, 1997; Park, 2020; Rosenfeld, 2006).

Moving on, a discussion of despotism would not be complete without looking at slavery. On that front, the available evidence seems to confirm what we expect: slave estates plumbed the depths of hierarchical despotism (Fig. 14). Again, we can frame this despotism in terms of accountability. In a slave hier- 
archy, there is none. In fact, slavery is probably the most extreme example of top-down hierarchical control. By definition, slaves have lost the right to hold their masters to account.

On that front, it is instructive to note that the mechanism that allowed slavery - namely ownership - is still used to wield power today. True, we no longer allow humans to be owned directly. But ownership remains the most common way of legitimizing hierarchical rule. Today, owners gain the right to rule not by buying people, but by buying an organization. When Jeff Bezos buys a start-up company, he purchases the right to rule its employees.

When it is framed this way, we see that ownership is a despotic institution. It enshrines the right of the owner to enforce their will on others. It follows that limiting hierarchical despotism requires regulating the power of owners and/or constraining ownership itself.

I will close on this topic with some startling evidence. Figure 17 looks at how income from ownership relates to the degree of hierarchical despotism in US firms. I plot here data from US CEOs (and their firms). The horizontal axis shows the portion of the CEO's income earned from stock options. Think of this portion as the degree to which the CEO is an owner, not an employee. The vertical axis shows the inferred degree of hierarchical despotism in the CEO's firm - the rate at which income grows with hierarchical power. The results are clear. As income from ownership increases, so does the degree of hierarchical despotism.

In some ways, the results in Figure 17 are surprising. The division of income into different 'types' is an accounting trick, and nothing more. Whether we call income 'salary', 'profit', or 'capital gains' follows from arbitrary accounting choices that are socially constructed. Why, then, should these arbitrary choices relate to the distribution of income?

The key is to realize two things: (1) income classification is arbitrary; (2) it is nonetheless connected to structures of power.

Throughout history, rulers have classified their income distinctly from the masses. When kings seized income from their subjects, they called it taxes. When churches did the same thing, it was called tithes. The point is not that these accounting classes are intrinsically meaningful. (They are not.) The point is that accounting classes are always connected to structures of power.

This is one of the essential insights of Jonathan Nitzan and Shimshon Bichler's theory of capital as power (Nitzan \& Bichler, 2009). Instead of trying to connect income to production (as both neoclassical and Marxist political economists 


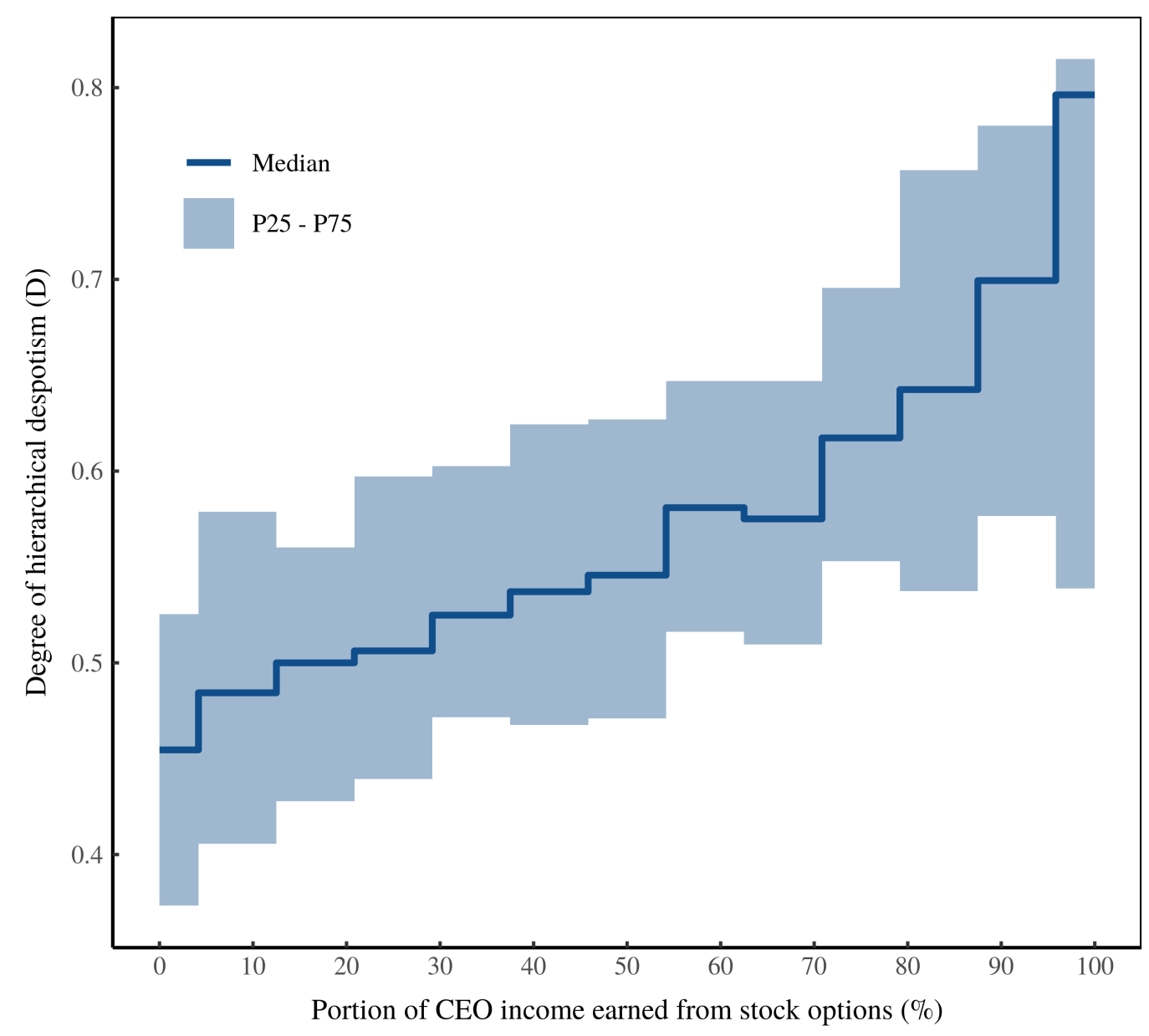

Figure 17: As CEOs become owners, firms tend to become more despotic

I plot here data for US CEOs. The horizontal axis shows the portion of the CEO's income that comes from stock options (i.e ownership income). The vertical axis shows the degree of hierarchical despotism $(D)$ in the firm, inferred from the CEO's pay and the firm's size. The resulting plot shows the trend across CEOs, binned by stock-option earnings. (Each step indicates a bin.) Sources and methods.

do), Nitzan and Bichler argue that income is a function of power. Today, power is wielded through ownership. And so attached to ownership we have a special class of income.

Like all forms of power, ownership is a tool for despotism. It follows that putting constraints on ownership will limit despotism. When framed this way, it is unsurprising that income from ownership relates to hierarchical despotism. When CEOs earn most of their income from stock options, it signals that they are owners, not employees. And this ownership, in turn, implies a lack of accountability. In contrast, when a CEO earns only a salary, it signals that they are 
an employee - a subordinate who is accountable to someone else.

To summarize, the mechanisms that produce pay inequality within hierarchies remain poorly understood. However, it seems plausible that hierarchies that manage to mitigate income inequality do so through a common tool. They counteract the despotic nature of the chain of command by imposing bottom-up accountability.

\section{The sustainable good life}

Humanity now sits at a unique place in the Earth's history. Never before has one species dominated the planet so completely. And never before has the behavior of a single species threatened to drive others to mass extinction (Kolbert, 2014). Modern humans wield power like never before. Unfortunately, we remain stuck, to a large extent, in the thinking of the past.

The expansionary ideology of modern society can likely be traced to the origins of civilization itself, when nature was transformed from something to live within to something to be conquered (Bowden, 2016). This ideology worked well when humanity was a speck of dust in the grand scheme of the biosphere. But today we are a veritable force of nature. That means the ideology of growth is no longer viable.

What should we do to fix the problem? Here the tools of science are in some ways inadequate. Never before has an industrial society reverted to a more sustainable format. And without concrete examples, science cannot tell us for certain what we should do. What seems clear, though, is that we must curb our fossil fuel habit. Barring some new Promethean technology (like nuclear fusion), the transition to renewable energy will likely also require using less energy. It will require degrowth.

Once unthinkable, the idea that we should voluntarily consume less is becoming more popular (Fournier, 2008; Kallis, 2011; Latouche, 2004). Most degrowth research, however, focuses on reducing individual levels of consumption. How such a reduction would affect the structure of society has been less discussed (an exception being Sorman \& Giampietro, 2013).

Looking at historical trends, I have argued that degrowth will likely entail a reduction in social hierarchy. The causal direction, however, remains unclear. It could be that reducing energy consumption will automatically lead to less hierarchy. Alternatively, it may be that reducing hierarchy would cause society to use less energy. This latter possibility deserves more research, because it 
suggests an indirect tool for achieving degrowth - replace large hierarchies with smaller institutions.

Regardless of how we reduce energy use, we should also seek to mitigate inequality. That is because it is equity that will make a sustainable society worth living in. Unfortunately, an equitable future is not guaranteed.

This fact is worth emphasizing. With its focus on the future, degrowth research often misses an important fact about humanity's past. The agrarian societies of old consumed far fewer resources than modern industrial civilization. And yet these agrarian societies were among the most unequal in history (Lenski, 1966). If we are not careful, future societies may retrace these early missteps. In other words, degrowth may lead not to an eco-utopia, but to neo-feudalism.

The key to limiting inequality, I have proposed, is to enforce accountability within hierarchies. Without this bottom-up flow of power, the hierarchical chain of command will tend towards despotism. On that front, we are surrounded by worrying signs. Today, the far right is resurging, bringing with it growing acceptance of autocratic rule (in the name of the people, of course). This hearkens to the fascism of the early 20th century. But the celebration of autocratic leaders probably has far deeper roots, dating to the origin of civilization itself.

To live the sustainable good life, then, is to chart a new direction for humanity - one that rejects both materialistic expansion and autocratic power. It will be difficult, yes. But that does not mean it is impossible. 


\section{Sources and methods}

Supplementary material for this paper are available at the Open Science Framework: osf.io/63bfs/. This includes source data as well as analysis/model code.

Data for average firm size (Fig. 1) comes from the Global Entrepreneurship Monitor. See the appendix in Fix (2017) for details. Data for energy use per capita comes from the World Bank, series EG . USE. PCAP . KG . OE. To these values I add an estimate for energy consumed through food (2000 kcal per day).

Data for managers' share of employment (Fig. 2) is from ILOSTAT Table TEM_OCU, series EMPoc1P.

The energy-manager model (Fig. 3) assumes that firms grow larger with energy use, as shown in Figure 1. Second, the model assumes that firms are hierarchically organized, where each superior controls the same number of subordinates - the 'span of control'. Third, the model assumes that managers occupy the top two hierarchical ranks. For details about the model, see Fix (2020a).)

Data for US electricity use per capita (Fig. 4) is from:

- US population, 1902-1959: Historical Statistics of the United States (HSUS) Millennial Addition, table Aa7.

- US population, 1960-present: World Bank, series SP. POP . TOTL

- US electricity use, 1902-1948: HSUS, table Db228 (indexed to EIA data in 1949)

- US electricity use, 1949-present: EIA series ELTCPUS

Data for the mean size of US power plants (Fig. 4) is calculated from EIA Form 860, 2019. In each year, I average the nameplate capacity of all active plants (including ones that are now retired, but still reported by the EIA).

Data for the size distribution of US electric power plants by energy source (Fig. 5) is also from EIA Form 860, 2019. It includes all plants active in 2019. I differentiate plants by the Technology field.

Data for relative income vs. hierarchical power (Fig. 7) are from:

- Cannon's Point Plantation: I estimate the hierarchical power of the plantation owners, and their income relative to the living standards of slaves (as inferred by 'expenditures on slaves'). Data is from Otto (1984). For details about the methods, see Fix (2019c).

- Case-Study Firms: Data is from Audas, Barmby, \& Treble (2004); Baker, Gibbs, \& Holmstrom (1993); Dohmen, Kriechel, \& Pfann (2004); Lima (2000); Morais \& Kakabadse (2014); Treble, Van Gameren, Bridges, \& 
Barmby (2001). For details about these studies, see the appendix in Fix (2019d).

- US CEOS: The data covers the years 2006-2016. CEO pay data is from Execucomp, series TOTAL_ALT2. I estimate the CEO's hierarchical power from firm size - Compustat series EMP. I plot, in Fig. 7, the CEO's income relative to the average employee. I estimate average income in the firm by dividing employment expenses (Compustat series XLR) by firm employment. (Compustat series EMP). For more details, see Fix (2020b). Note that the CEO data is not strictly comparable to the other series in Fig. 7 because it measures pay to relative to the firm average. All other series, however, measure pay relative to the average in the bottom rank of the hierarchy.

- US military: Data is from annual demographics reports (Demographics: Profile of the Military Community) between 2010 and 2019. I exclude warrant officers from the data. I calculate the pay within each rank as the average of the minimum and maximum pay by years of experience. For details, see my blog post How Hierarchy Can Mediate the Returns to Education.

Data for the span of control in real-world institutions (Fig. 9) is from:

- Firm aggregate studies: Data is from Ariga, Brunello, Ohkusa, \& Nishiyama (1992); Bell \& Van Reenen (2012); Eriksson (1999); Heyman (2005); Mueller, Ouimet, \& Simintzi (2016); Rajan \& Wulf (2006). For details about these studies, see the appendix in Fix (2019d).

- Firm case studies: Data is from Audas et al. (2004); Baker et al. (1993); Dohmen et al. (2004); Lima (2000); Morais \& Kakabadse (2014); Treble et al. (2001). For details about these studies, see the appendix in Fix (2019d).

- US military: Data is from annual demographics reports (Demographics: Profile of the Military Community) between 2010 and 2019.

Estimates for the degree of hierarchical despotism in real-world institutions (Fig. 14) are calculated by regressing the logarithm of relative income onto the logarithm of hierarchical power. Data sources:

- US military: Data is from annual demographics reports (Demographics: Profile of the Military Community) between 2010 and 2019. 
- Firm case studies: Data is from Audas et al. (2004); Baker et al. (1993); Dohmen et al. (2004); Lima (2000); Morais \& Kakabadse (2014); Treble et al. (2001). For details about these studies, see the appendix in Fix (2019d).

- US CEOS: The data covers the years 2006-2016. I estimate hierarchical despotism using the CEO pay ratio and firm size. I assume that CEO's firms have a span of control of 3 - the same as the average found in firm case studies. I then use my model of hierarchy to infer the parameter $D$ that would produce the observed CEO pay ratio, given the firm's size. CEO pay data is from Execucomp, series TOTAL_ALT2. I estimate the CEO's hierarchical power from firm size - Compustat series EMP. I estimate average income in the firm by dividing employment expenses (Compustat series XLR) by firm employment. (Compustat series EMP). For more details, see Fix (2020b).

In Fig. 17, data for the share of CEO income coming from stock options is calculated by dividing actual realized gains from stock options (Execucomp series SHRS_VEST_VAL + OPT_EXER_VAL) by total compensation (Execucomp series TOTAL_ALT2). See Fix (2020b) for details.

\section{Hierarchy model}

The model of hierarchy used in this paper is based on equations derived independently by Herbert Simon (1957) and Harold Lydall (1959). In this model, hierarchies have a constant span of control. We assume that there is one person in the top rank. The total membership in the hierarchy is then given by the following geometric series:

$$
N_{T}=1+s+s^{2}+\ldots+s^{n-1}
$$

Here $n$ is the number of ranks, $s$ is the span of control, and $N_{T}$ is the total membership. Summing this geometric series gives:

$$
N_{T}=\frac{1-s^{n}}{1-s}
$$

In my model of hierarchy, the input is the hierarchy size $N_{T}$ and the span of 
control $s$. To model the hierarchy, we must first estimate the number of hierarchical ranks $n$. To do this, we solve the equation above for $n$, giving:

$$
n=\left\lfloor\frac{\log \left[1+N_{T}(s-1)\right]}{\log (s)}\right\rfloor
$$

Here \lfloor\rfloor denotes rounding down to the nearest integer. Next we calculate $N_{1}$ - the employment in the bottom hierarchical rank. To do this, we first note that the firm's total membership $N_{T}$ is given by the following geometric series:

$$
N_{T}=N_{1}\left(1+\frac{1}{s}+\frac{1}{s^{2}}+\ldots+\frac{1}{s^{n-1}}\right)
$$

Summing this series gives:

$$
N_{T}=N_{1}\left(\frac{1-1 / s^{n}}{1-1 / s}\right)
$$

Solving for $N_{1}$ gives:

$$
N_{1}=N_{T}\left(\frac{1-1 / s}{1-1 / s^{n}}\right)
$$

Given $N_{1}$, membership in each hierarchical rank $h$ is:

$$
N_{h}=\left\lfloor\frac{N_{1}}{s^{h-1}}\right\rfloor
$$

Sometimes rounding errors cause the total employment of the modeled hierarchy to depart slightly from the size of the original input value. When this happens I add/subtract members from the bottom rank to correct the error.

Once the hierarchy has been constructed, income $(I)$ is a function of hierarchical power:

$$
I=\left(\bar{P}_{h}\right)^{D}
$$

Here $D$ is the 'degree of hierarchical despotism' - a free parameter that determines how rapidly income grows with hierarchical power. $\bar{P}_{h}$ is the average hierarchical power (per person) associated with rank $h$. It is defined as

$$
\bar{P}_{h}=1+\bar{S}_{h}
$$


where $\bar{S}_{h}$ is the average number of subordinates per member of rank $h$ :

$$
\bar{S}_{h}=\sum_{i=1}^{h-1} \frac{N_{i}}{N_{h}}
$$

The model is implemented numerically in $\mathrm{C}++$, using the Armadillo linear algebra library (Sanderson \& Curtin, 2016). For R users, I have created R functions implementing the model, available at Github:

- github.com/blairfix/hierarchy

- github.com/blairfix/hierarchical_power 


\section{References}

Ariga, K., Brunello, G., Ohkusa, Y., \& Nishiyama, Y. (1992). Corporate hierarchy, promotion, and firm growth: Japanese internal labor market in transition. Journal of the Japanese and International Economies, 6(4), 440-471.

Atwood, M. (2006). The handmaid's tale (Vol. 301). Everymans Library.

Audas, R., Barmby, T., \& Treble, J. (2004). Luck, effort, and reward in an organizational hierarchy. Journal of Labor Economics, 22(2), 379-395.

Baker, G., Gibbs, M., \& Holmstrom, B. (1993). Hierarchies and compensation: A case study. European Economic Review, 37(2-3), 366-378.

Baran, P. A., \& Sweezy, P. M. (1966). Monopoly capital: An essay on the American economist and social order. New York: Monthly Review Press.

Barroso, F. G., Alados, C. L., \& Boza, J. (2000). Social hierarchy in the domestic goat: Effect on food habits and production. Applied Animal Behaviour Science, 69(1), 35-53.

Bell, B., \& Van Reenen, J. (2012). Firm performance and wages: Evidence from across the corporate hierarchy. CEP Discussion Paper, 1088.

Bentley, G. R., Goldberg, T., \& Jasieńska, G. yna. (1993). The fertility of agricultural and non-agricultural traditional societies. Population Studies, 47(2), 269-281.

Bhandari, K. P., Collier, J. M., Ellingson, R. J., \& Apul, D. S. (2015). Energy payback time (epbt) and energy return on energy invested (EROI ) of solar photovoltaic systems: A systematic review and meta-analysis. Renewable and Sustainable Energy Reviews, 47, 133-141.

Bichler, S., \& Nitzan, J. (2020). Growing through sabotage: Energizing hierarchical power. Review of Capital as Power, 1(5), 1-78.

Boehm, C. (2009). Hierarchy in the forest: The evolution of egalitarian behavior. Cambridge, MA: Harvard University Press.

Boehm, C., Barclay, H. B., Dentan, R. K., Dupre, M.-C., Hill, J. D., Kent, S., ... Rayner, S. (1993). Egalitarian behavior and reverse dominance hierarchy 
[and comments and reply]. Current Anthropology, 34(3), 227-254.

Boix, C., \& Rosenbluth, F. (2014). Bones of contention: The political economy of height inequality. American Political Science Review, 1-22.

Bowden, B. (2016). Civilization and its consequences.

Crawford, N. C. (2019). Pentagon fuel use, climate change, and the costs of war. Watson Institute, Brown University.

Dahrendorf, R. (1959). Class and class conflict in industrial society. Stanford: Stanford University Press.

Davis, K., \& Moore, W. E. (1945). Some principles of stratification. American Sociological Review, 10(2), 242-249.

DiNardo, J. E., Hallock, K. F., \& Pischke, J.-S. (1997). Unions and managerial pay. NBER Working Paper, (w6318).

Dohmen, T. J., Kriechel, B., \& Pfann, G. A. (2004). Monkey bars and ladders: The importance of lateral and vertical job mobility in internal labor market careers. Journal of Population Economics, 17(2), 193-228.

Dunbar, R. I. (1992). Neocortex size as a constraint on group size in primates. Journal of Human Evolution, 22(6), 469-493.

Dunbar, R. I. (2009). The social brain hypothesis and its implications for social evolution. Annals of Human Biology, 36(5), 562-572.

Ehrlich, P. R., \& Ehrlich, A. H. (2013). Can a collapse of global civilization be avoided? Proceedings of the Royal Society B: Biological Sciences, 280(1754), 
20122845.

Ehrlich, P. R., \& Holdren, J. P. (1971). Impact of population growth. Science, 171 (3977), 1212-1217.

Eriksson, T. (1999). Executive compensation and tournament theory: Empirical tests on Danish data. Journal of Labor Economics, 17(2), 262-280.

Fix, B. (2015a). Putting power back into growth theory. Review of Capital as Power, 1(2), 1-37.

Fix, B. (2015b). Rethinking economic growth theory from a biophysical perspective. New York: Springer.

Fix, B. (2017). Energy and institution size. PLOS ONE, 12(2), e0171823.

Fix, B. (2019a). An evolutionary theory of resource distribution. Real-World Economics Review, (90), 65-97.

Fix, B. (2019b). Dematerialization through services: Evaluating the evidence. BioPhysical Economics and Resource Quality, 4(2), 1-17.

Fix, B. (2019c). Energy, hierarchy and the origin of inequality. Plos One, 14(4), e0215692.

Fix, B. (2019d). Personal income and hierarchical power. Journal of Economic Issues, 53(4), 928-945.

Fix, B. (2020a). Economic development and the death of the free market. https: //doi.org/doi:10.31235/osf.io/g86am

Fix, B. (2020b). How the rich are different: Hierarchical power as the basis of income size and class. Journal of Computational Social Science, 1-52.

Fix, B., Bichler, S., \& Nitzan, J. (2019). Ecological limits and hierarchical power. Real-World Economics Review Blog.

Foster, J. B. (2011). Capitalism and degrowth: An impossibility theorem. Monthly Review, 62(8), 26-33.

Fournier, V. (2008). Escaping from the economy: The politics of degrowth. International Journal of Sociology and Social Policy, 28(11/12), 528-545.

Guhl, A. M., Collias, N. E., \& Allee, W. C. (1945). Mating behavior and the social hierarchy in small flocks of white leghorns. Physiological Zoology, 18(4), 
365-390.

Hall, C. A., Lambert, J. G., \& Balogh, S. B. (2014). EROI of different fuels and the implications for society. Energy Policy, 64, 141-152.

Hawken, P. (2000). Natural capitalism: Creating the next industrial revolution. Boston: Little.

Hayden, B. (2001). Richman, poorman, beggarman, chief: The dynamics of social inequality. In Archaeology at the millennium (pp. 231-272). Springer.

Heinberg, R. (2007). Peak everything. Gabriola Island.

Herbert, S. (1962). The architecture of complexity. Proceedings of the American Philosophical Society, 106(6), 467-482.

Heyman, F. (2005). Pay inequality and firm performance: Evidence from matched employer-employee data. Applied Economics, 37(11), 1313-1327.

Hill, K. R., Walker, R. S., Božičević, M., Eder, J., Headland, T., Hewlett, B., ... Wood, B. (2011). Co-residence patterns in hunter-gatherer societies show unique human social structure. Science, 331(6022), 1286-1289.

Jacobson, M. Z., Delucchi, M. A., Bauer, Z. A., Goodman, S. C., Chapman, W. E., Cameron, M. A., ... others. (2017). 100\% clean and renewable wind, water, and sunlight all-sector energy roadmaps for 139 countries of the world. Joule, 1(1), 108-121.

Jacobson, M. Z., Delucchi, M. A., Bazouin, G., Bauer, Z. A., Heavey, C. C., Fisher, E., ... Yeskoo, T. W. (2015). 100\% clean and renewable wind, water, and sunlight (wws) all-sector energy roadmaps for the 50 United States. Energy \& Environmental Science, 8(7), 2093-2117.

Joskow, P. L., Rose, N. L., \& Wolfram, C. D. (1996). Political constraints on executive compensation: Evidence from the electric utility industry. The RAND Journal of Economics, 165-182.

Joskow, P., Rose, N., Shepard, A., Meyer, J. R., \& Peltzman, S. (1993). Regulatory constraints on CEO compensation. Brookings Papers on Economic Activity. 
Microeconomics, 1993(1), 1-72.

Kallis, G. (2011). In defence of degrowth. Ecological Economics, 70(5), 873880.

Kolbert, E. (2014). The sixth extinction: An unnatural history. A\&C Black.

Kondo, S., \& Hurnik, J. F. (1990). Stabilization of social hierarchy in dairy cows. Applied Animal Behaviour Science, 27(4), 287-297.

Latouche, S. (2004). Degrowth economics. Le Monde Diplomatique, 11, 2004.

Lenski, G. E. (1966). Power and privilege: A theory of social stratification. Chapel Hill: UNC Press Books.

Lima, F. (2000). Internal labor markets: A case study. FEUNL Working Paper, 378.

Lydall, H. F. (1959). The distribution of employment incomes. Econometrica: Journal of the Econometric Society, 27(1), 110-115.

Marglin, S. A. (1974). What do bosses do? The origins and functions of hierarchy in capitalist production. Review of Radical Political Economics, 6(2), $60-112$.

Marx, K. (1867). Capital, volume I. Harmondsworth: Penguin/New Left Review.

Meese, G. B., \& Ewbank, R. (1973). The establishment and nature of the dominance hierarchy in the domesticated pig. Animal Behaviour, 21 (2), 326-334.

Mills, C. W. (1956). The power elite. Oxford: Oxford University Press.

Morais, F., \& Kakabadse, N. K. (2014). The corporate Gini index (cgi) determinants and advantages: Lessons from a multinational retail company case study. International Journal of Disclosure and Governance, 11(4), 380-397.

Mueller, H. M., Ouimet, P. P., \& Simintzi, E. (2016). Within-firm pay inequality. SSRN Working Paper.

Nitzan, J., \& Bichler, S. (2009). Capital as power: A study of order and creorder. New York: Routledge.

Otto, J. S. (1984). Cannon's point plantation, 1794-1860: Living conditions and status patterns in the old south. Toronto: Academic Press Inc.

Palmer, G., \& Floyd, J. (2017). An exploration of divergence in epbt and EROI for solar photovoltaics. BioPhysical Economics and Resource Quality, 2(4), 
$1-20$.

Park, M. (2020). Unionized employees' influence on executive compensation: Evidence from Korea. British Journal of Industrial Relations.

Parsons, T. (1940). An analytical approach to the theory of social stratification. American Journal of Sociology, 45(6), 841-862.

Price, T. D., \& Feinman, G. M. (1995). Foundations of social inequality (Vol. 1). New York: Springer Science \& Business Media.

Price, T. D., \& Feinman, G. M. (Eds.). (2010). Pathways to power: New perspectives on the emergence of social inequality. New York: Springer.

Rajan, R. G., \& Wulf, J. (2006). The flattening firm: Evidence from panel data on the changing nature of corporate hierarchies. The Review of Economics and Statistics, 88(4), 759-773.

Rosenfeld, J. (2006). Widening the gap: The effect of declining unionization on managerial and worker pay, 1983-2000. Research in Social Stratification and Mobility, 24(3), 223-238.

Sanderson, C., \& Curtin, R. (2016). Armadillo: A template-based C++ library for linear algebra. Journal of Open Source Software, 1(2), 26.

Sapolsky, R. M. (2005). The influence of social hierarchy on primate health. Science, 308(5722), 648-652.

Simon, H. A. (1957). The compensation of executives. Sociometry, 20(1), 3235.

Sober, E., \& Wilson, D. S. (1999). Unto others: The evolution and psychology of unselfish behavior. Harvard University Press.

Sorman, A. H., \& Giampietro, M. (2013). The energetic metabolism of societies and the degrowth paradigm: Analyzing biophysical constraints and realities. Journal of Cleaner Production, 38, 80-93.

Sweezy, P. M. (1942). The theory of capitalist development: Principles of Marxian political economy. New York: Oxford University Press.

Treble, J., Van Gameren, E., Bridges, S., \& Barmby, T. (2001). The internal economics of the firm: Further evidence from personnel data. Labour Economics, 
$8(5), 531-552$.

Tumin, M. M. (2018). Some principles of stratification: A critical analysis. In Inequality (pp. 7-20). Routledge.

Turchin, P. (2016). Ultrasociety: How 10,000 years of war made humans the greatest cooperators on Earth. Chaplin, Connecticut: Beresta Books.

Turchin, P., \& Gavrilets, S. (2009). Evolution of complex hierarchical societies. Social Evolution and History, 8(2), 167-198.

Uhrich, J. (1938). The social hierarchy in albino mice. Journal of Comparative Psychology, 25(2), 373.

Weizsäcker, E. U. v. (1997). Factor four: Doubling wealth, halving resource use: The new report to the Club of Rome. London: Earthscan Publications.

Wilkinson, R. G. (2001). Mind the gap: Hierarchies, health and human evolution. Yale University Press.

Wilkinson, R. G. (2002). Unhealthy societies: The afflictions of inequality. Routledge.

Wilkinson, R. G., \& Pickett, K. (2009). The spirit level: Why more equal societies almost always do better. New York: Penguin Books.

Wilson, D. S. (2015). Does altruism exist? Culture, genes, and the welfare of others. Yale University Press. 